\title{
RIP1/RIP3-regulated necroptosis as a target for multifaceted disease therapy (Review)
}

\author{
YUPING LIU $^{1 *}$, TING LIU $^{2 *}$, TIANTIAN LEI ${ }^{2 *}$, DINGDING ZHANG ${ }^{2,3^{*}}$, SUYA DU $^{4 *}$, \\ LEA GIRANI $^{* *}$, DANDAN $\mathrm{QI}^{2}, \mathrm{CHEN} \mathrm{LIN}^{2}$, RONGSHENG TONG ${ }^{5}$ and YI WANG $^{1,5}$
}

\begin{abstract}
${ }^{1}$ Health Management Center, Sichuan Academy of Medical Science and Sichuan Provincial People's Hospital, Chengdu, Sichuan 610072; ${ }^{2}$ School of Medicine, University of Electronic Science and Technology of China, Chengdu, Sichuan 610054; ${ }^{3}$ Key Laboratory for Genetics of Human Disease, Sichuan Academy of Medical Science and Sichuan Provincial People's Hospital, Chengdu, Sichuan 610072; ${ }^{4}$ Department of Clinical Pharmacy, Sichuan Cancer Hospital and Institute, Sichuan Cancer Center, School of Medicine, University of Electronic Science and Technology of China, Chengdu, Sichuan 610054; ${ }^{5}$ Personalized Drug Therapy Key Laboratory of Sichuan Province, Department of Pharmacy, Sichuan Academy of Medical Science and Sichuan Provincial People's Hospital, Chengdu, Sichuan 610072, P.R. China
\end{abstract}

Received December 24, 2018; Accepted June 11, 2019

DOI: $10.3892 /$ ijmm.2019.4244

\begin{abstract}
Necroptosis is a type of programmed cell death with necrotic morphology, occurring in a variety of biological processes, including inflammation, immune response, embryonic development and metabolic abnormalities. The current nomenclature defines necroptosis as cell death mediated by signal transduction from receptor-interacting serine/threonine kinase (RIP) 1 to RIP3 (hereafter called RIP1/RIP3). However, RIP3-dependent cell death would be a more precise definition of necroptosis. RIP3 is indispensable for necroptosis, while RIP1 is not consistently involved in the signal transduction. Notably, deletion of RIP1 even promotes RIP3-mediated necroptosis under certain conditions. Necroptosis was previously thought as an alternate process of cell death in case of apoptosis inhibition. Currently, necroptosis is recognized to serve a pivotal role in regulating various physiological processes. Of note, it mediates a variety of human diseases, such as ischemic brain injury, immune system disorders and cancer. Targeting and inhibiting necroptosis, therefore, has the
\end{abstract}

Correspondence to: Dr Yi Wang, Health Management Center, Sichuan Academy of Medical Science and Sichuan Provincial People's Hospital, 32 West Ring Road, Chengdu, Sichuan 610072, P.R. China

E-mail:w_yi@yahoo.com

Dr Rongsheng Tong, Personalized Drug Therapy Key Laboratory of Sichuan Province, Department of Pharmacy, Sichuan Academy of Medical Science and Sichuan Provincial People's Hospital, 32 West Ring Road, Chengdu, Sichuan 610072, P.R. China

E-mail: tongrs@126.com

*Contributed equally

Key words: necroptosis, receptor-interacting serine/threonine kinase 1, receptor-interacting serine/threonine kinase 3, pathological mechanisms, disease therapy potential to be used for therapeutic purposes. To date, research has elucidated the suppression of RIP1/RIP3 via effective inhibitors and highlighted their potential application in disease therapy. The present review focused on the molecular mechanisms of RIP1/RIP3-mediated necroptosis, explored the functions of RIP1/RIP3 in necroptosis, discussed their potential as a novel therapeutic target for disease therapy, and provided valuable suggestions for further study in this field.

\section{Contents}

1. Introduction

2. Structural characteristics of RIP1/RIP3

3. Molecular mechanisms of RIP1/RIP3-regulated necroptosis

4. Functional features of RIP1/RIP3 in necroptosis

5. Necroptosis, a timoneer of pathological mechanisms

6. RIP1/RIP3 inhibition in necroptosis

7. Application potential of RIP1/RIP3 inhibition in disease therapy

8. Conclusion and perspectives

\section{Introduction}

With the rapid development of research in the field of cellular death, it is acknowledged that necrosis can also be regulated in a programmed manner via a specific signal transduction pathway called necroptosis or programmed necrosis $(1,2)$. Necroptosis-mediated cell rupture is morphologically characterized by the loss of cell plasma membrane and the swelling of organelles (particularly mitochondria). Nevertheless, necroptosis, a form of programmed cell death (PCD), and its upstream molecular signaling pathways are under strict control $(3,4)$. The initiation of necroptosis requires several different stimuli, as well as the kinase activity of receptor-interacting serine/threonine kinase 1 (RIP1) and receptor-interacting serine/threonine kinase 3 (RIP3) (5). 
The human RIP gene, located on chromosome 6p25.2, encodes seven splicing isoforms: RIP1, RIP2, RIP3, RIP4, RIP5, RIP6 and RIP7 (6). RIP1 was initially identified in 1995 as a protein that interacted with the death domain (DD) of receptor Fas (CD95) and elicited a characteristic programmed death response in susceptible cells (7). In 1997, RIP3 was discovered as a protein attenuating both RIP1 and tumor necrosis factor receptor 1 (TNFR1)-induced NF- $\kappa \mathrm{B}$ activation (8). RIP1 and RIP3 are critical signaling molecules in necroptosis and regulated by the caspase pathway and ubiquitination (9). Ubiquitination of RIP1 activates NF- $\mathrm{BB}$ and mitogen-activated protein kinases (MAPKs), leading to cell survival, while deubiquitinated RIP1 induces the caspase-8-mediated apoptosis pathway (3). When caspase-8 is inhibited or deficient, RIP1 combines with RIP3 via the C-terminal RIP homotypic interaction motif (RHIM) domain to form the RIP1/RIP3 complex (10). The complex initiates downstream signal transduction and triggers necroptosis (10). Excessive necroptosis can cause embryonic lethality (11) and initiate multiple human diseases, including, but not limited to, systemic inflammation, ischemic reperfusion injury and neurodegeneration (12).

The present review examined the functions of RIP1/RIP3-regulated necroptosis on multifaceted pathological mechanisms. Furthermore, the importance of RIP1/RIP3 in determining the cell outcome was highlighted by the interactive molecular pathways noted among cell survival, apoptosis and necroptosis. Then, the pivotal roles of RIP1/RIP3 in disease treatment were discussed, highlighting their application potential as new drug targets.

\section{Structural characteristics of RIP1/RIP3}

Structurally, RIP1 and RIP3 share nearly half of their amino acid sequences and have very similar topology features. The RIP1 protein consists of 671 amino acids (Homo sapiens). It contains a N-terminal serine/threonine kinase domain, an intermediate domain (ID), a RHIM and a C-terminal DD (13) (Fig. 1A). RIP3 is composed of 518 amino acids (Homo sapiens), and contains a N-terminal kinase domain similar to that of RIP1, a RHIM domain and a unique C-terminus without a DD (14) (Fig. 1A). RIP1 acts as a multifunctional adaptor protein in response to the activated signal of death receptors (DRs), and its DD binds to the DRs of TNFR1, Fas and TNF-related apoptosis inducing ligand (TRAIL) $(15,16)$. It mediates prosurvival NF- $\kappa B$ activation, caspase-dependent apoptosis and RIP kinase-dependent necroptosis (17). The ID of RIP1 contains the RHIM that enables the protein to combine with RIP3. In contrast to RIP1, RIP3 is not directly required for DR-induced cell survival or death (18). RIP3 binds to RIP1 through its unique C-terminal segment to inhibit RIP1 and TNFR1-mediated NF- $\mathrm{KB}$ activation (19) (Fig. 1B). Experiments have revealed that tumor necrosis factor (TNF) induces the formation of an RIP1/RIP3 complex, indicating that RIP1 interacts with RIP3 through the homotypic RHIM domain (20).

\section{Molecular mechanisms of RIP1/RIP3-regulated necroptosis}

Necroptosis can provide a substitute suicide mechanism in case of malfunction of the classical apoptosis machinery (21). Most work on necroptosis concerns studies of TNF signaling. TNF is a pleiotropic cytokine that has an essential role in inflammation, tissue injury and cell death (22). In the TNF receptor superfamily, researchers have found six human DRs, including TNFR1, Fas (also known as CD95 or APO-1), DR3 (also known as TRAMP or APO-3), TRAIL receptor 1 (TRAILR1, also known as DR4), TRAIL receptor 2 (TRAILR2, also known as DR5, TRICK or KILLER) and DR6 (also known as CD358) (23-26). However, the most prevalent pathway is the TNFR1-mediated signal transduction, which can propel cell survival, apoptosis and necroptosis (27). The present review focused on the three most dominant of those TNF-mediated pathways.

Different modifications of RIP1 can induce distinct outcomes of cell survival, apoptosis and necroptosis. Following binding of TNF- $\alpha$ to TNFR1 at the plasma membrane, TNF-receptor-associated death domain (TRADD) recruits downstream proteins, namely RIP1, the E3 ubiquitin ligases TNF-receptor-associated factor (TRAF) 2, TRAF5, and the cellular inhibitor of apoptosis (cIAP) 1 and cIAP2, to form the complex I $(28,29)$. Then, the complex I mediates NF- $\kappa B$ and MAPK signaling, contributing to cell survival or other non-death functions $(4,30,31)$. The K63-linked ubiquitination of RIP1 by cIAP1/2 promotes both the formation and activation of the transforming growth factor-activated kinase 1 (TAK1)-binding protein (TAB) complex and the inhibitor of $\mathrm{NF}-\kappa \mathrm{B}$ kinase (IKK) complex (consisting of NF- $\kappa \mathrm{B}$ essential modulator, IKK $\alpha$ and IKK $\beta$ ), supporting the NF- $\kappa B$ pathway activation, and ultimately leading to cell survival (1) (Fig. 2).

Complex I internalizes and transforms into a death-inducing complex II following caspase-8 activation (29). Two distinct types of complex II (IIa and IIb) can be distinguished based on their composition and the activity of their proteins. After dissociating from TNFR1, TRADD recruits Fas-associated protein with death domain (FADD) and further promotes recruitment and activation of caspase-8 to form the complex IIa $(29,32)$. Activation of caspase- 8 subsequently induces apoptosis independently of RIP1 or its kinase activity (32). In certain circumstances, including upon the absence of cIAP1/2, upon inhibition of IAP mediated by a small molecule mimic of diablo IAP-protein mitochondrial protein (33) and upon auto-degradation of cIAP1/2, RIP1 is released from complex I to form a caspase-8-activating complex (complex IIb) which mediates apoptosis (32). Complex IIb consists of RIP1, RIP3, FADD and the FLICE-like inhibitory protein long form (FLIPL)/caspase- 8 heterodimer, and it promotes RIP1- and caspase-8-dependent apoptosis (22). Hence, RIP1 is not an indispensable factor in apoptosis, although the process is favored by its presence. Under physiological levels, the caspase-8/FLIPL heterodimer facilitates caspase-8 oligomer assembly to trigger apoptosis. By contrast, high levels of FLIPL and FLICE-like inhibitory protein short form (FLIPS) restrict caspase-8/c-FLIPL/S heterodimer activity, leading to inhibition of apoptosis (34-36). Inactivation of RIP1 and RIP3, mediated by cleavage via caspase-8/FLIPL heterodimer in Complex IIb, inhibits necroptosis $(37,38)$ (Fig. 2).

When caspase- 8 is inhibited by zVAD, RIP1 and RIP3 are combined via the RHIM, and form complex IIc, also known as the necrosome (39). Complex IIc is a crucial cytoplasmic signaling complex, which does not appear in the TNF-induced 
A
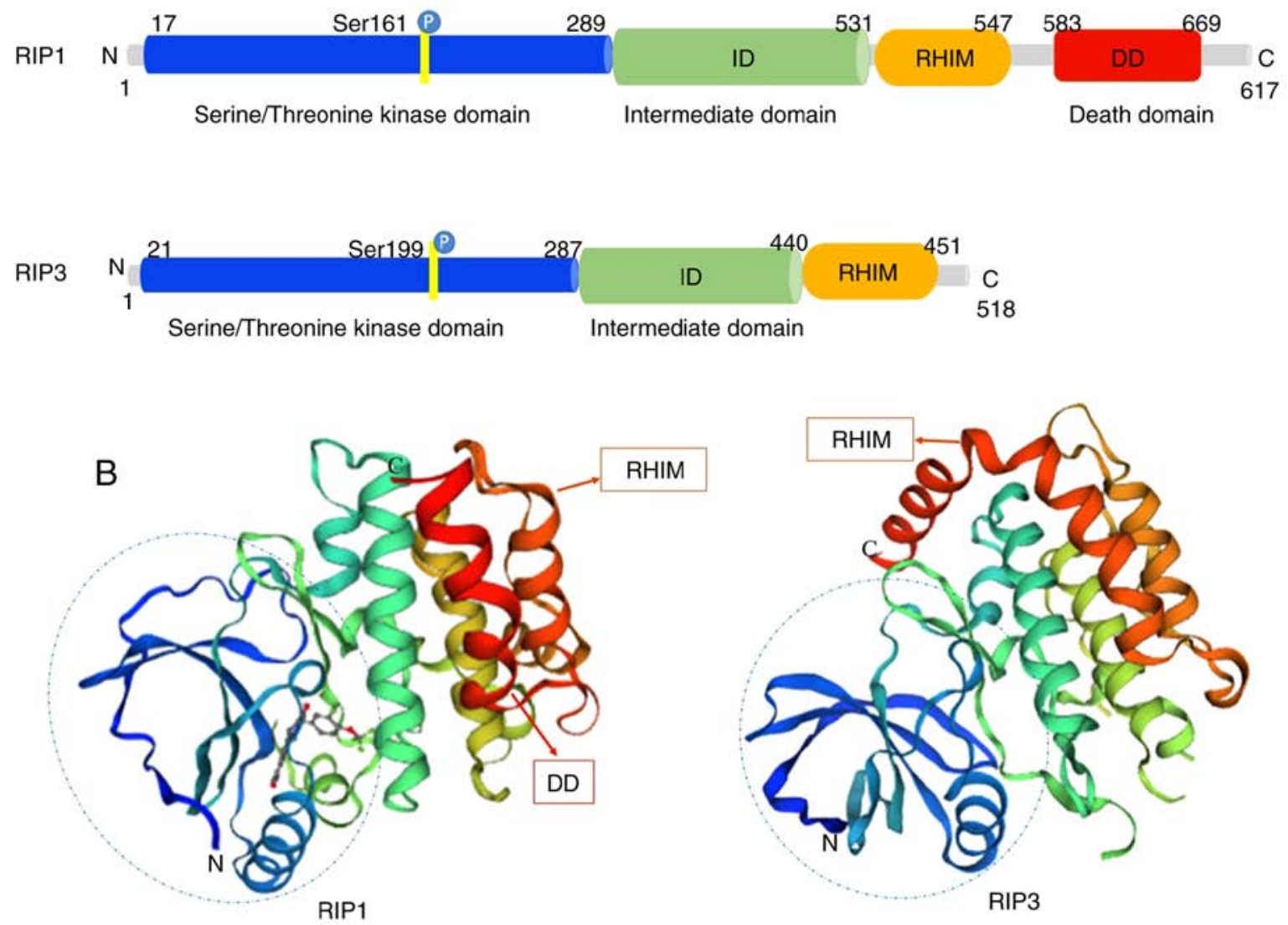

Figure 1. Structural diagrams of RIP1 and RIP3. (A) Schematic of functional domains of RIP1 and RIP3. (B) Protein tertiary structures of RIP1 and RIP3. RIP, receptor-interacting serine/threonine kinase; ID, intermediate domain; RHIM, RIP homotypic interaction motif; DD, death domain.

cell survival or apoptosis $(10,40)$. Mitochondrial reactive oxygen species (ROS) oxidize RIP1 at three crucial cysteine sites (C257, C268 and C586), and promote autophosphorylation of RIP1 at Ser161. RIP1 autophosphorylation is pivotal for the recruitment of RIP3 (41). In addition, CYLD lysine 63 deubiquitinase (CYLD), as a deubiquitinase removing polyubiquitin chains from RIP1, facilitates the formation and activation of RIP1/RIP3 necrosomes by deubiquitylating RIP1. When CYLD is deficient, necrosomes promote a high level of ubiquitinated RIP1 and block phosphorylation of RIP1 and RIP3 $(32,42)$. Furthermore, the RHIM is also required for the RIP1/RIP3 complex formation (19). After RIP1 and RIP3 are combined, RIP1 gets phosphorylated by RIP3 (10). Intramolecular auto- and trans-phosphorylation of RIP1/RIP3 promotes recruitment of another key necroptosis-signaling protein, the mixed lineage kinase domain like protein (MLKL). MLKL is then phosphorylated by RIP3 to initiate necroptosis (43). The phosphorylated MLKL is transferred from the cytosol to the plasma and intracellular membranes via the four helical bundle-brace (4HBD-BR) regions of MLKL (44). The oligomerization of MLKL causes membrane pore formation, resulting in the destruction of membrane integrity and eventually leading to necrotic death (45) (Fig. 2).

In addition to the classic TNFR1-induced necroptosis pathway described above, toll-like receptors (TLR) can also mediate necroptosis. The TLR signaling pathway is generally triggered by pathogen-associated molecular patterns during viral or microbial infection $(46,47)$. TLR-mediated necroptosis results in the destruction of infected cells and is thus beneficial to the host. The downstream MLKL signaling pathway of RIP3 is indispensable for both TNFR1- and TLR-induced signaling (46), and caspase-8 can block necroptosis that is directly initiated by the TIR domain-containing interferon- $\beta$ (TRIF)/RIP3/MLKL pathway $(48,49)$. TLR4 and TLR3 are respectively activated by lipopolysaccharide (LPS) (50) and polyinosine-polycytidylic acid (I:C), a synthetic double stranded RNA (dsRNA) mimic (51). Thereafter, TLR3 and TLR4 activate RIP3 and participate in ensuing necroptosis via TRIF or MyD88 (52-54). The C-terminal RHIM motif is required for RIP3 to interact with TRIF or MyD88. The RIP3/TRIF signaling complex recruits and phosphorylates MLKL, inducing ROS accumulation and mediating TLR3and TLR4-induced necroptosis (46,47) (Fig. 3).

Increasing numbers of necroptotic stimuli have been identified and divided into two groups: RIP1-dependent and RIP1-independent (Fig. 3). RIP1-dependent stimuli include TNF- $\alpha$, Fas, TRAIL, interferon (IFN) $-\alpha$ and IFN- $\beta$. The primary death-inducing signaling complex (DISC) is assembled by stimulation of Fas or TRAILR at the plasma membrane, thereby activating caspase- 8 and triggering apoptosis independently of RIP1 (55). cIAP deficiency promotes the recruitment of RIP1 and Fas when caspase- 8 is blocked, and enhances the formation of the cytosolic ripoptosome complex which induces necroptosis (56). In bone-marrow-derived macrophages, type I IFN $\alpha$ and IFN $\beta$ bind to their cognate receptor IFN $\alpha / \beta$ receptor subunit 1 (IFNAR1) to activate Janus kinase 1 and form the IFN-stimulated gene factor 3 (ISGF3) complex (consisting of STAT1, STAT and IFN-regulatory factor 9). The 


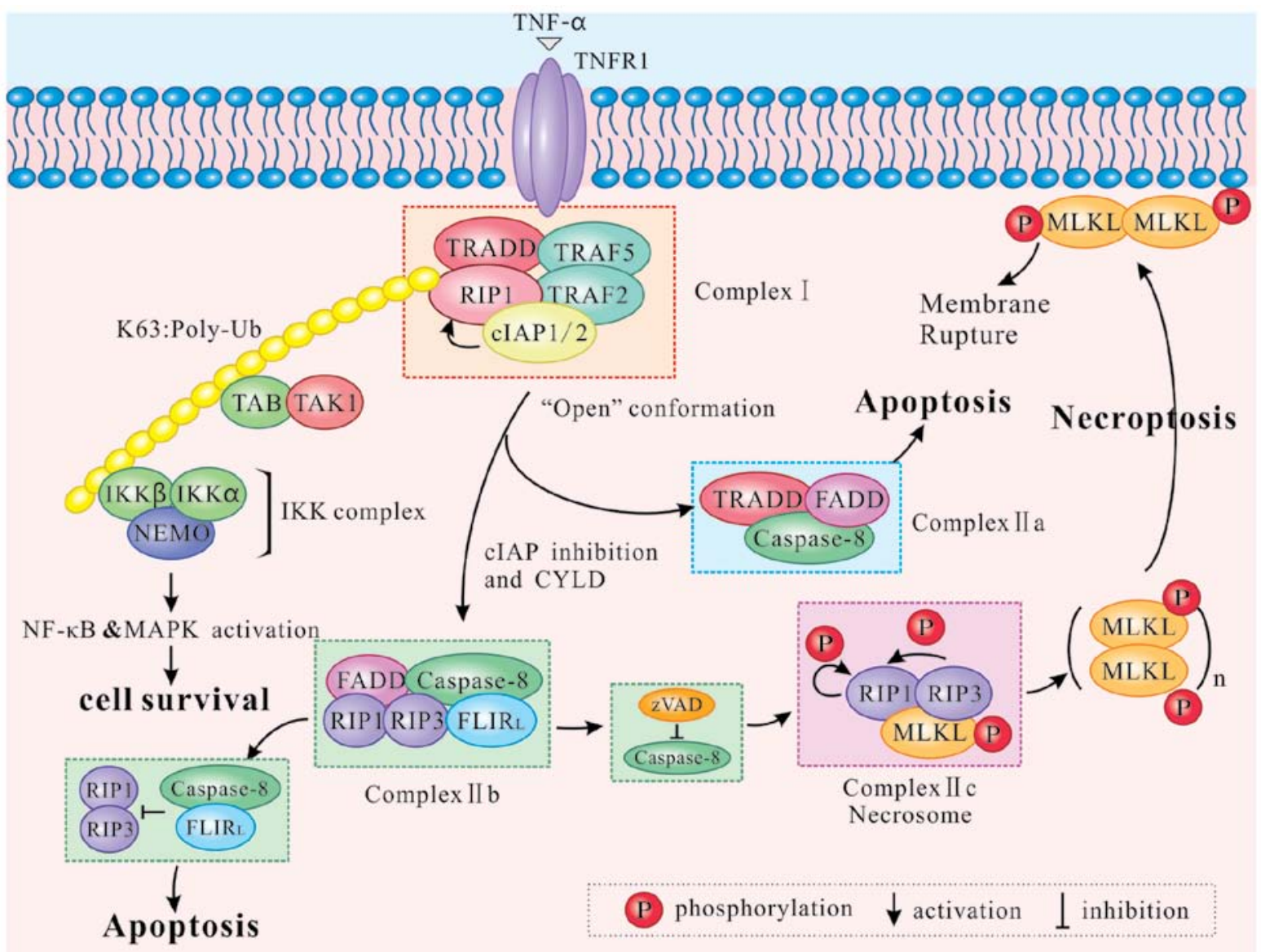

Figure 2. TNFR1-mediated signaling pathways. After the binding of TNF to its receptor, TNFR1 undergoes a conformational change and recruits multiple proteins to form complex I, consisting of TRADD, TRAF2/5, RIP1 and cIAP1/2. The K63-linked ubiquitination of RIP1 by cIAP1/2 promotes the formation and activation of the TAK1/TAB complex and the IKK $\alpha / \mathrm{IKK} \beta / \mathrm{NEMO}$ complex, which induced the NF- $\mathrm{BB}$ pathway and cell survival. Destabilization of complex I results in the formation of complex IIa, that contains TRADD, FADD and caspase-8. When cIAPs are blocked and RIP1 deubiquitylated by CYLD, complex IIb is formed. This consists of RIP1, RIP3, FADD, caspase- 8 and FLIPL. Both IIa and IIb can initiate apoptosis. When caspase- 8 is inhibited by chemical caspase inhibitors, RIP1 binds to RIP3, resulting in the formation of RIP1/RIP3 by intramolecular auto- and trans-phosphorylation. Then, RIP3 recruits and phosphorylates MLKL to form complex IIc, conventionally referred to as the necrosome. The phosphorylated MLKL then translocates from the cytosol to the plasma and intracellular membranes. The oligomerization of MLKL results in membrane pore formation, causing membrane rupture and eventually necroptosis. TNFR1, TNF receptor 1; TNF, tumor necrosis factor; TRADD, TNF-receptor-associated death domain; TRAF, TNF-receptor-associated factor; RIP, receptor-interacting serine/threonine kinase; cIAP, cellular inhibitor of apoptosis 1; TAK1, transforming growth factor-activated kinase 1; TAB, TAK1-binding protein; IKK, inhibitor of NF-אB kinase; NEMO, NF- $\mathrm{kB}$ essential modulator; FADD, Fas-associated protein with death domain; CYLD, CYLD lysine 63 deubiquitinase; FLIPL, FLICE-like inhibitory protein long form; MLKL, mixed lineage kinase domain like protein.

ISGF3 complex promotes induction and activation of necrosomes, and triggers necroptosis in a transcription-dependent pathway (57). RIP1-independent stimuli generally refer to LPS, dsRNA and viruses. DNA-dependent activator of IFN regulatory factors (DAI) can identify viral dsRNA, promote the recruitment of RIP3 to form necrosomes without RIP1, and induce RIP3-dependent necroptosis (58). Illuminating the molecular mechanisms involved in necroptosis will elucidate further the molecular biology underlying the pathology.

\section{Functional features of RIP1/RIP3 in necroptosis}

RIP1 and RIP3 were recently delineated as two important effectors in the cell death network, as they are cascade proteins responding to complex TNFR signaling and regulating cellular survival, apoptosis and necroptosis. It is important to note that RIP3 is indispensable for necroptosis, whereas RIP1 is not. TNF- $\alpha$-induced RIP1/RIP3 interaction engages
RIP3 recruitment, leading to RIP3/RIP3 homo-oligomerization and RIP3 autophosphorylation. Phosphorylated RIP3 recruits and phosphorylates MLKL, which promotes MLKL oligomer-executed necroptosis (59). However, the directorial functions of RIP1 are not always positive for RIP3. Researchers have constructed RIP3 dimers and RIP3 oligomers to analyze how RIP1 induces the activation of RIP3 (60). The results demonstrated that the dimerization of RIP3 alone was insufficient to induce the cell death. The RIP3 dimer seeded a RHIM-dependent complex controlled by both caspase- 8 and RIP1. On the other hand, without TNF stimulation and RIP1 activity, the oligomerization of RIP3 was sufficient to induce necroptosis (60). These results indicated that RIP1 not only activates RIP3 in response to TNF signaling, but also participates in cytoprotection. TNFR1 promotes the activation of the NF- $\mathrm{BB}$ pathway, $\mathrm{p} 38 \alpha$ and its downstream effector MAPK-activated protein kinase 2 kinase (MK2), thereby promoting cell survival (61). Recently, Jaco et al (62) reported 


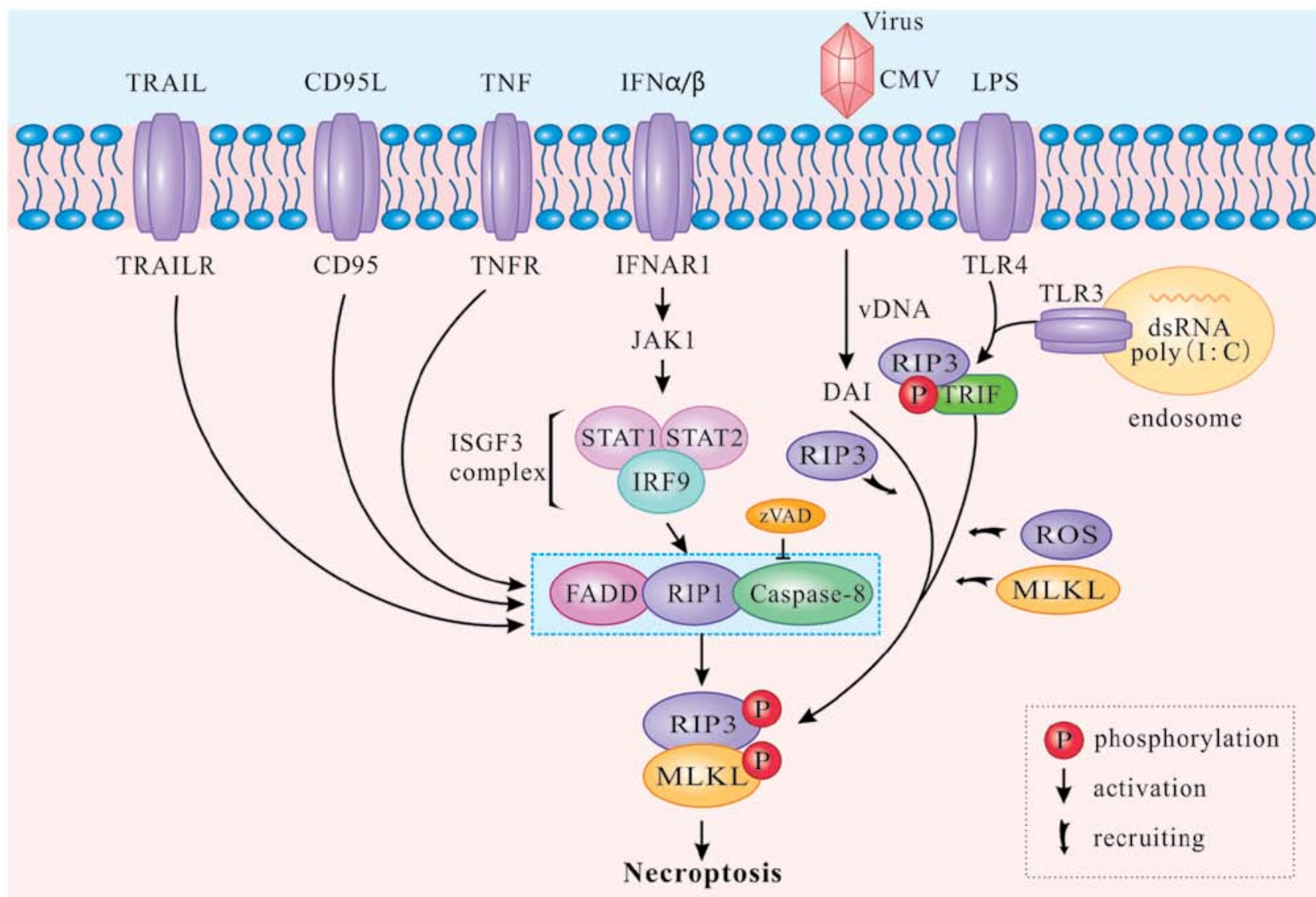

Figure 3. Other stimuli leading to necroptosis. In addition to the TNF- $\alpha$-mediated necroptosis pathway, multiple other necroptosis triggers have been identified. These involve the canonical pathway that requires RIP1 kinase activity, as well as the non-canonical pathway that is dependent on either the TRIF adaptor or the DAI sensor. RIP1-dependent stimuli include TNF- $\alpha$, CD95L (also known as FASL), APO-1L, TRAIL (also known as APO-2L) and IFN- $\alpha / \beta$. RIP1-independent stimuli include viruses (such as CMV), viral DNA, LPS and polycytidylic acid. After various necroptotic stimuli induce necroptosis, a necrosome is formed. Phosphorylated MLKL by RIP3 transfers from the cytosol to the plasma and intracellular membranes, causing destruction of membrane integrity and eventually necrotic death. TNF, tumor necrosis factor; RIP, receptor-interacting serine/threonine kinase; TRIF, TIR domain-containing interferon- $\beta$; DAI, DNA-dependent activator of IFN regulatory factors; FASL, Fas ligand; TRAIL, TNF-related apoptosis inducing ligand; IFN, interferon; CMV, cytomegalovirus; LPS, lipopolysaccharide; MLKL, mixed lineage kinase domain like protein.

that activated MK2 phosphorylated RIP1 at Ser321 to synergize TNF-induced cell rescue. Therefore, these results suggest that RIP1 serves as a positive checkpoint within TNF stimulation that integrates cytokine production and cell survival. RIP1 is therefore thought as an inhibitor rather than an initiator of RIP3-induced necroptosis (63).

Furthermore, ROS participate in the regulation of necroptosis in many cell types, and enhance the formation of necrosomes induced by Smac mimetic bivalent 6 compound (BV6)/TNF $\alpha$ (64). BV6/TNF $\alpha$-stimulated ROS generation promotes the stabilization of the RIP1/RIP3 feedback loop. A previous study demonstrated that the metabolic enzymes glycogen phosphorylase (PYGL), glutamate dehydrogenase 1 (GLUD1), and glutamate-ammonia ligase (GLUL), are activated by RIP3 (65). Enhancement of aerobic respiration is mediated by TNF-induced ROS. However, the major mechanism of ROS and RIP1/RIP3 remains not completely understood. A recent study demonstrated that mitochondrial ROS activated RIP1 autophosphorylation at Ser161 via oxidation of three crucial cysteines in RIP1 (41). This phosphorylation accelerated RIP1 recruitment of the RIP3 aggregation and formed a necrosome, which then resulted in mitochondrial depolarization and cell necroptosis (66). These studies provided essential insight into the reciprocal regulation between RIP1/RIP3 and ROS in necroptosis.

\section{Necroptosis, a timoneer of pathological mechanisms}

Role of necroptosis in inflammation. Necroptosis, as a novel pathway of PCD, leads to release of endogenous moldecules from disrupted dying cells, that subsequently triggers inflmmation and immune response (67). Necroptosis-inducing factors include TLR3 and TLR4 agonists [such as interleukin (IL)-1 $\beta$ )], TNF, certain viral infections and $\mathrm{T}$ cell receptors (22). TNF-mediated and TLR-mediated signaling pathways are the primary pathways for necroptosis, both regulated by RIP3 (10). RIP1/RIP3 or RIP3/TRIF signaling complexes recruit and phosphorylate downstream MLKL, causing rupture of the plasma membrane, as well as the release of endogenous molecules (45). These endogenous molecules are known as damage-associated molecular patterns (DAMPs). They are also identified as part of the extended IL-1 family (IL- $1 \alpha$, IL-1 $\beta$, IL-18, IL-33, IL-36 $\alpha, \beta$ and $\gamma$ ) (68). The leakage of DAMPs can activate inflammasomes, facilitate 


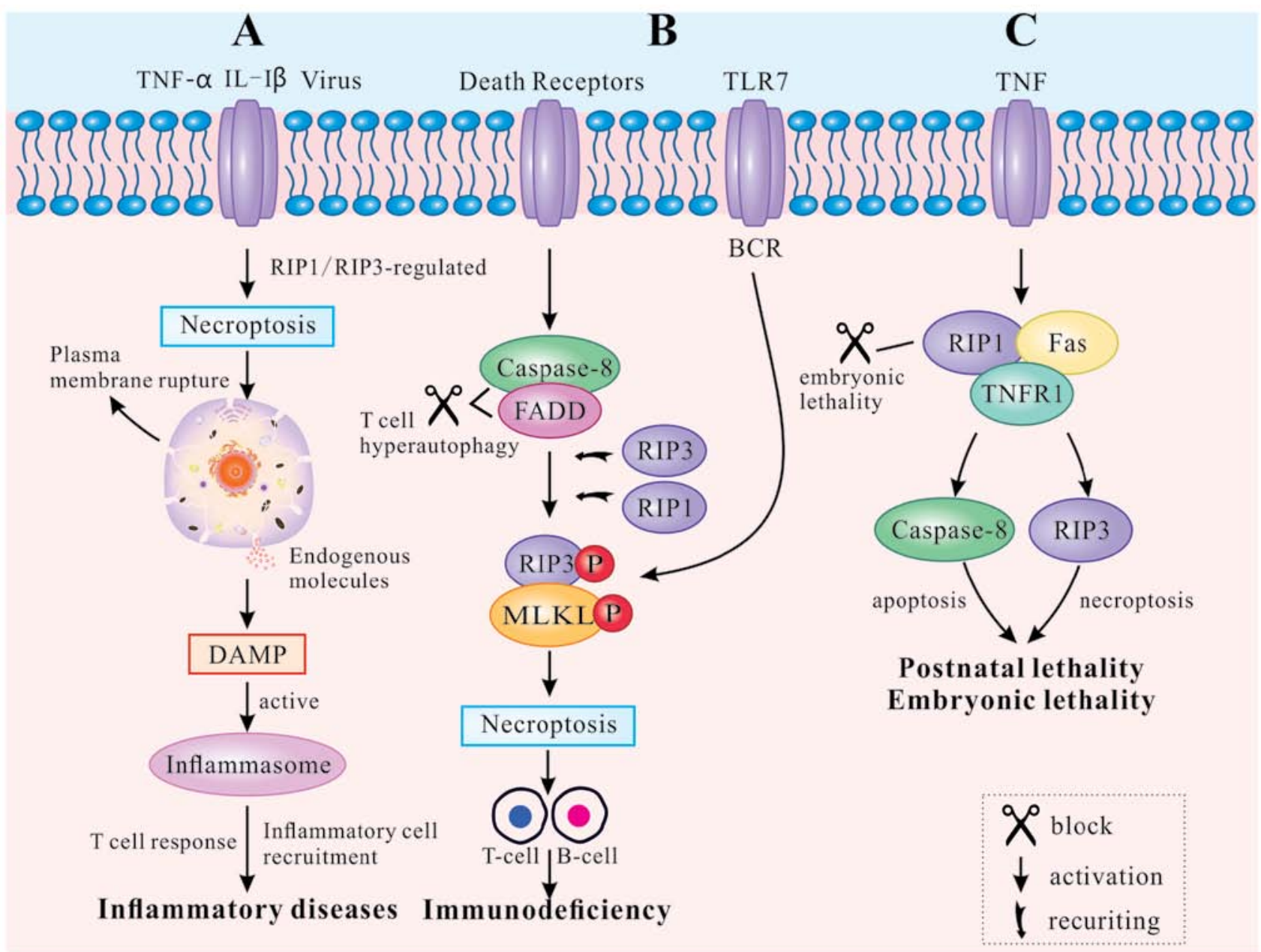

Figure 4. Necroptosis-associated pathological mechanisms. (A) Inflammatory factors include TNF- $\alpha$ and IL-1 $\beta$. Certain viral infections can induce RIP1/RIP3-mediated necroptosis, which can result in the disruption of the plasma membrane and in the release of endogenous molecules, also known as DAMPs. Inflammasomes are then activated by DAMPs, promoting inflammatory cell recruitment and virus-specific T cell responses to induce inflammatory diseases. (B) DRs can regulate the necroptosis of T and B cells. When either caspase-8 or FADD is deficient, T cells undergo hyper-autophagy and generate a RIP1/RIP3-mediated necrosome, triggering necroptosis. BCR mediates necroptosis via reaction with TLR7. Necroptosis of T lymphocytes and B lymphocytes can cause immunodeficiency. (C) RIP1 prevents embryonic and postnatal lethality by blocking two different cell death pathways: FADD/caspase-8-mediated apoptosis and RIP3-mediated necroptosis. TNF, tumor necrosis factor; IL, interleukin; RIP, receptor-interacting serine/threonine kinase; DAMPs, damage-associated molecular patterns; DR, death receptor; FADD, Fas-associated protein with death domain; BCR, B cell receptor; TLR, toll-like receptor; MLKL, mixed lineage kinase domain like protein; TNFR1, TNF receptor 1.

inflammatory cell recruitment to the site of infection, and promote subsequent virus-specific $\mathrm{T}$ cell responses to induce inflammation (69). Thus, regulating the mechanism of necroptosis can result in both inhibition and promotion of the immune response (Fig. 4A).

Role of necroptosis in immunity. DRs regulate necroptosis in various cell types, such as B lymphocytes and T lymphocytes, both of which are essential for immune homeostasis and tolerance $(48,70)$. Blocked DRs fail to clear activated lymphocytes and unbalanced lymphoid homeostasis, ultimately leading to autoimmune lymphoproliferative syndrome (ALPS) (71). FADD, caspase- 8 and RIP kinases are indispensable for T cell clonal expansion, contraction and antiviral responses (48). When caspase- 8 and FADD are deficient, T cells undergo hyper-autophagy and proliferative inhibition in response to antigenic stimulation. In addition, $\mathrm{T}$ cells generate necrosomes, which induce caspase-8-independent necroptosis (72). RIP1 and RIP3 are either recruited by DRs or by other cellular signaling molecules, including DNA damage and antigen receptor ligation (73). Chronic necroptosis may be the basis of human fibrotic and autoimmune disorders (74). Likewise, $\mathrm{B}$ cell receptor (BCR) mediates necroptosis via reaction with TLR7 to prevent autoimmune diseases $(75,76)$. The RIP1 inhibitor necrostatin-1 (nec-1) has been demonstrated to suppress B-cell necroptosis, when pretreating B cells from patients with systemic lupus erythematosus (70). Fig. 4B illustrates how programmed death can promote clonal loss of lymphocytes during infection and protect patients against autoimmune disease.

Effects of necroptosis on animal development. Apoptosis and necroptosis are closely associated with embryonic lethality and postnatal development (49). RIP1 determines cell survival or death by associating with TNFR1, TLRs and Fas (17,77). Embryonic lethality of RelA-deficient mice has been demonstrated to be mediated by apoptosis and necroptosis (78). FADD functions as an adaptor to induce apoptosis by 
recruiting and activating caspase-8 (79). The characteristics of FADD-deficient embryos are high levels of RIP1 production and massive necrosis. RIP1 ablation allows normal embryogenesis in FADD-deficient mice, but these mice usually die around their first postnatal day (80). In addition, different RIP1 kinase inactivating mutations have distinct effects on the embryogenesis of FADD-deficient mice. For example, RIP1K45A has been found not to prevent the embryonic lethality of FADD-deficient mice, while RIP1 $\Delta$ (with an altered P-loop in the kinase domain) does (81). If RIP1 was necessary for the activation of RIP3, as aforementioned, FADD $^{-/-} \mathrm{RIP}^{-/-}$ and FADD ${ }^{-/}$RIP3 $^{-/}$mice should survive to adulthood (82). Nevertheless, a recent study revealed that RIP1-deficient mice die soon after birth, leading to speculation for the positive role of RIP1 in embryonic development and postnatal life (83). RIP1 deletion enhances primary cell sensitivity to FADD/caspase-8-mediated apoptosis induced by TNF. In addition, RIP1 deletion promotes RIP3/MLKL-mediated necroptosis induced by TLR ligation (via TRIF) or interferon (84). The perinatal lethality of RIP1/- mice can be rescued by a combination of additional mutations. A recent study indicated that haploid insufficiency of RIP3 improved the survival period of $\mathrm{RIP1}^{-/-} \mathrm{FADD}^{-/-}$double knockout mice beyond weaning age, while RIP1 ${ }^{-/-} \mathrm{FADD}^{-/} \mathrm{RIP}^{-/-}$triple knockout (TKO) mice were significantly smaller in size and weight (85). Furthermore, complete ablation of RIP3 further prolonged the life span of TKO mice displaying normal size and weight (85). Therefore, it can be concluded that RIP1 may prevent postnatal lethality by blocking two different cell death pathways: FADD/caspase-8-mediated apoptosis and RIPK3/MLKL-mediated necroptosis. The effect of PCD on animal development is highly complex and has not yet been thoroughly elucidated (Fig. 4C).

\section{RIP1/RIP3 inhibition in necroptosis}

Inhibitors of RIP1 and RIP3. The increasing discovery of inhibitors and drugs affecting the RIP1/RIP3 cascade pathway already shows promise towards the treatment of various diseases (Table I). Nec-1 has been identified as a specific and potent small-molecule and active inhibitor of RIP1 (2). Nec-1 is widely used in disease models to examine the contribution of RIP1 to cell death and inflammation. Other necrostatins, including Nec-3, Nec-4 and Nec-5, also stabilize RIP1 in an inactive conformation through interactions with hydrophobic pockets and highly conserved amino acids $(2,86)$. However, the strongest inhibition of RIP1 has been observed with Nec-1 stable (Nec-1s) (87). A previous study identified GSK2982772 (compound 5) as a novel inhibitor of RIP1 (88). GSK2982772 potently binds to RIP1 with exquisite kinase specificity and has high activity in blocking TNF-dependent necroptosis, as well as inflammation. Based on this previous study of GSK2982772, Yoshikawa et al (27) designed and synthesized a novel class of RIP1 kinase inhibitor, the compound 22 [7-oxo-2,4,5,7-tetrahydro-6H-pyrazolo(3,4-c)pyridine], which possesses moderate RIP1 kinase inhibitory activity and P-gp mediated efflux. Furthermore, using a mouse model of systemic inflammatory response syndrome, it was demonstrated that compound 56 (RIPA-56) targeted RIP1 directly, and reduced $\mathrm{TNF} \alpha$-induced cell mortality and multi-organ damage (89). The pan-Aurora kinase inhibitor Tozasertib (also known as VX-680 and MK-0457) was recently demonstrated as a potent compound in inhibition of RIP1-dependent necroptosis and in the blockage of cytokinesis in cells (90). The food and drug administration-approved anticancer agents ponatinib and pazopanib were demonstrated to be submicromolar inhibitors of necroptosis through the targeting of components upstream of MLKL (91). Ponatinib inhibits both RIP1 and RIP3, while pazopanib preferentially targets RIPK1. Both drugs have potential values for the treatment of pathology caused or aggravated by necroptotic cell death (91). Overall, the aforementioned studies indicated that RIP1 kinase may serve as a novel target for therapeutic drug development in human disease therapy.

RIP3 is a critical regulator of necroptosis, however, very few specific inhibitors have yet been reported. B-Raf (V600E) inhibitors are generally considered as an important anticancer drug in metastatic melanoma therapy (92). To date, the B-Raf inhibitor dabrafenib was demonstrated to be a potent inhibitor of RIP3 (92). Dabrafenib decreased RIP3-mediated Ser358 phosphorylation of MLKL and disrupted the interaction between RIP3 and MLKL (93). Results indicated that dabrafenib could serve as a RIP3 inhibitor and as a potential preventive or therapeutic agent for RIP3-involved necroptosis-related diseases (93). As expected, dabrafenib significantly reduced infarct lesion size and attenuated upregulation of TNF- $\alpha$ in mouse models of ischemic brain injury (94). In addition, murine cytomegalovirus (CMV) M45 contains a RHIM domain, and was confirmed to be a competitive inhibitor of RIP3 (95). Human CMV blocks TNF-induced necroptosis following RIP3 activation and MLKL phosphorylation (95), leading to inhibition of the host defense mechanism.

MicroRNA (miRNA)-associated inhibition by targeting RIPI/RIP3. As diagnostic and therapeutic strategies, miRNAs provide a novel perspective for RIP1 inhibition. As aforementioned, several inhibitors have been demonstrated to suppress the pro-necroptosis function of RIP1 at the protein level; however, these do not function at the mRNA level. miR-155 represses cardiomyocyte progenitor cell necroptosis by targeting RIP1 rather than activating the Akt pro-survival pathway (96), suggesting that miR-155 might be a novel approach in improving cell engraftment. Additionally, in a myocardial ischemia/reperfusion model, it was demonstrated that miR-103/107, as a necrosis-suppressor miRNA, directly targeted FADD $(97,98)$. FADD participates in hydrogen peroxide-induced necroptosis by influencing the formation of RIP1/RIP3 complex, suggesting that FADD-targeting by miR-103/107 might be a new approach for preventing myocardial necrosis. Recent research has indicated that miRNA dysregulation is involved in triple-negative breast cancer (TNBC) (100). Overexpression of miR-182 inhibits the CYLD action on the ubiquitin chains on RIP1, leading to caspase-8-dependent apoptosis in TNF- $\alpha$-treated TNBC cells (99). Additionally, miR-145, which is downregulated in TNBC, targeted cIAP1 and reduced the formation of the RIP1/FADD-caspase-8 complex (100). Therefore, miRNAs can be perceived as a novel approach for RIP1 regulation. However, their potential effects in disease intervention requires further research (Table II). 
Table I. Direct and indirect inhibitors of RIP1/RIP3.

\begin{tabular}{|c|c|c|c|}
\hline Compound & Targeted proteins & Applications & (Refs.) \\
\hline Nec-1 & RIP1 & $\begin{array}{l}\text { Nec- } 1 \text { is the most active, compared with } \\
\text { Nec- } 3 \text {, Nec- } 4 \text { and Nec-5 }\end{array}$ & (2) \\
\hline GSK2982772 (compound 5) & RIP1 & $\begin{array}{l}\text { Phase } 2 \text { a clinical studies for rheumatoid } \\
\text { arthritis and ulcerative colitis }\end{array}$ & $(88)$ \\
\hline $\begin{array}{l}\text { 7-oxo-2,4,5,7-tetrahydro-6H- } \\
\text { pyrazolo }[3,4-\mathrm{c}] \text { pyridine } \\
\text { (compound } 22 \text { ) }\end{array}$ & RIP1 & $\begin{array}{l}\text { Oral administration }(10 \mathrm{mg} / \mathrm{kg} \text {, twice a day) } \\
\text { attenuated disease progression in a mouse } \\
\text { experimental autoimmune encephalomyelitis } \\
\text { model of multiple sclerosis }\end{array}$ & $(27)$ \\
\hline RIPA-56 (compound 56) & RIP1 & $\begin{array}{l}\text { For the treatment of systemic inflammatory } \\
\text { response syndrome }\end{array}$ & $(89)$ \\
\hline $\begin{array}{l}\text { Tozasertib (also called as } \\
\text { VX-680 and MK-0457) }\end{array}$ & pan-Aurora kinase, RIP1 & Protects against TNF-induced necroptosis & $(90)$ \\
\hline Ponatinib & RIP1, RIP3 & $\begin{array}{l}\text { Ponatinib can directly bind RIP1 and block } \\
\text { RIP3 autophosphorylation }\end{array}$ & $(91)$ \\
\hline Pazopanib & Preferentially targets RIP1 & $\begin{array}{l}\text { Similar to Nec-1, RIP1 is the main target of } \\
\text { pazopanib }\end{array}$ & $(91)$ \\
\hline Dabrafenib & RIP3, B-Raf (V600E) & Alleviates acetaminophen-induced liver injury & $(93)$ \\
\hline Murine cytomegalovirus M45 & RIP3 & Binds to RIP3 through RHIM domain & $(95)$ \\
\hline Kongensin $\mathrm{A}$ & HSP90 (indirectly inhibits RIP3) & $\begin{array}{l}\text { Kongensin A covalently binds to HSP90 and } \\
\text { inhibits the stability of RIP3/MLKL }\end{array}$ & $(102)$ \\
\hline Compound 17AAG & HSP90 (indirectly inhibits RIP3) & $\begin{array}{l}\text { Promotes degradation of MLKL and RIP3 } \\
\text { through the proteasome pathway }\end{array}$ & $(104)$ \\
\hline Alvespimycin (17-DMAG) & $\begin{array}{l}\text { HSP90 (indirectly inhibits } \\
\text { RIP1/RIP3) }\end{array}$ & Destabilizes the necroptosis proteins RIP1 and RIP3 & $(105)$ \\
\hline Dyngo 4a & TLR4 (indirectly inhibits RIP3) & $\begin{array}{l}\text { Blocks the internalization of TLR } 4 \text { and prevents } \\
\text { RIP3-induced necroptosis of macrophages }\end{array}$ & $(108)$ \\
\hline
\end{tabular}

RIP, receptor-interacting serine/threonine kinase; Nec, necrostatin; TNF, tumor necrosis factor; RHIM, RIP homotypic interaction motif; HSP90, heat shock protein 90; MLKL, mixed lineage kinase domain like protein; TLR4, Toll-like receptor 4.

Table II. Applications of targeting miRNAs in necroptosis.

\begin{tabular}{|c|c|c|c|}
\hline miRNA & Targeted mRNAs & Sequence $\left(5^{\prime}-3^{\prime}\right)$ & (Refs.) \\
\hline miR-155 & RIP1 & UUAAUGCUAAUUGUGAUAGGGG & $(96)$ \\
\hline miR-103 & FADD & AGCAGCAUUGUACAGGGCUAUGA & $(97,98)$ \\
\hline miR-107 & FADD & AGCAGCAUUGUACAGGGCUAUCA & $(98)$ \\
\hline $\operatorname{miR}-182$ & CYLD & UUUGGCAAUGGUAGAACUCACACU & (99) \\
\hline $\operatorname{miR}-145$ & cIAP1 & GUCCAGUUUUCCCAGGAAUCCCUGGAUUCCUGGGAAAA CUGGACUU & (100) \\
\hline
\end{tabular}

miRNA, microRNA; RIP, receptor-interacting serine/threonine kinase; FADD, Fas-associated protein with death domain; CYLD, CYLD lysine 63 deubiquitinase; cIAP1, cellular inhibitor of apoptosis 1 .

Indirect inhibition of RIPI/RIP3. Previously, Li et al (101) revealed that the cochaperone complex of HSP90 and CDC37 regulated the stability and function of RIP3 and MLKL, and participated in the RIP3 activation process during necroptosis. The HSP90 inhibitor kongensin A (KA) disrupted the association of HSP90 and CDC37, leading to the inhibition of RIP3-dependent necroptosis $(101,102)$. These results suggested that KA was an effective HSP90 inhibitor with a potential anti-RIP3 effect in both RIP3-dependent necroptosis and inflammation. In addition, the disruption of HSP90 function 
prevented necrosome formation, reduced MLKL phosphorylation and inhibited TNF-induced necroptosis (103). The compound 17AAG destabilized the interaction of MLKL and RIP3 by inhibiting HSP90, resulting in degradation of MLKL and RIP3 via the proteasome pathway (104). Alvespimycin (17-DMAG), an inhibitor of HSP90, facilitated the degradation of RIP3 following HSP90 inactivation (105). Therefore, pharmacological modulation of RIP3-induced necroptotic cell death through HSP90 could be a promising strategy for therapy in several settings (Table I).

In TNF $\alpha$-induced necroptosis, as RIP1 and RIP3 form a protein complex through their common RHIM domain, phosphorylation and activation of RIP3 and downstream MLKL occur (106). In addition, RHIM-containing proteins, such as TLR, and interferon regulatory factors (Z-DNA binding protein 1, also known as DAI or DLM1) are known to activate RIP3 and further transduce necrosis signals to MLKL (107). TLR3 or TLR4 directly activate necroptosis through the RHIM-dependent association of TRIF with RIP3. This pathway proceeds independently of RIP1, but remains dependent on MLKL downstream of RIP3 kinase (46). Dyngo 4a blocks the internalization of TLR4 and prevents RIP3-induced necroptosis of macrophages (108). A previous study unveiled DAI as the RIP3 partner to interact with RIP3, mediating virus-induced necrosis analogous to the RIP1/RIP3 complex controlling TNF-induced necroptosis (109). Table I summarizes the direct and indirect inhibitors of RIP3.

\section{Application potential of RIP1/RIP3 inhibition in disease therapy}

RIP1/RIP3-dependent necroptosis in cardiovascular disease. Necroptosis participates in the development of several diseases, such as atherosclerosis cardiovascular disease, a leading cause of mortality worldwide (110). Overexpression of RIP3 during necroptosis of primary macrophages induced by oxidized LDL (ox-LDL) facilitates the development of the disease (111). Furthermore, monoclonal antibodies can be detected in the core of atherosclerotic plaques, specifically recognizing the phosphorylation form of RIP3 at Ser232 (112). Notably, the mortality of apolipoprotein E/RIP3 double-knockout mice was delayed dramatically (112). These findings indicated that RIP3-mediated necroptosis in atherosclerotic plaques may release pro-inflammatory cytokines that exacerbate atherosclerosis. Of note, PS-341, a potent and specific proteasome inhibitor, was demonstrated to impair macrophage necroptosis through stabilization of cIAPs and disruption of the formation of the RIP1/RIP3 complex (113).

RIP1 inhibition leads to a reduction of infarct size, implying a functional importance of necroptosis in myocardial ischemia (MI) (114). Luedde et al (20) analyzed RIP3 expression in murine hearts and highlighted the potential functional significance of RIP3-dependent necroptosis in the modulation of post-ischemic adverse remodeling in MI. A previous study demonstrated that RIP3 was upregulated in murine hearts subjected to ischemia-reperfusion (IR) injury, as well as in cardiomyocytes treated with LPS and hydrogen peroxide (115). This study further illustrated that upregulated RIP3 evoked endoplasmic reticulum (ER) stress, ultimately resulting in cardiomyocyte necroptosis in the setting of cardiac
IR injury (115). In addition, in a mouse cardiac hypertrophy model established by transverse abdominal aortic constriction, both mRNA and protein expression levels of RIP1 and RIP3 were increased significantly. Losartan downregulated the expression of RIP1/RIP3, resulting in the inhibition of necroptosis and to the alleviation of cardiac hypertrophy (116). RIP1/RIP3 may thus be an attractive target for future therapies that aim to limit the adverse consequences of cardiac disease.

The quaternary nitrogen herbicide paraquat is a highly toxic pro-oxidant that triggers oxidative stress and multi-organ failure, including that of the heart. Recently, Zhang et al (117) revealed that Nec-1 pretreatment prevented cardiac contractile dysfunction, reduced RIP1/RIP3 interaction, downregulated the RIP1/RIP3/MLKL signaling pathway, and dramatically inhibited the production of ROS in paraquat-challenged mice. Thus, the RIP1/RIP3/MLKL signaling cascade may represent an innovative therapeutic direction for paraquat poisoning-induced cardiac contractile dysfunctions (Table III).

RIPI/RIP3-dependent necroptosis in cancer therapy. Abundant research on RIP1/RIP3 has highlighted its role in cancer, which is due to its necroptosis-inducing function (118). Chen et al (119) have noted that necroptosis is a critical cell-killing mechanism in response to severe stress and blocked apoptosis, and have proposed that it can serve as an alternative cell death program to prevent cancer. Previous studies have indicated that increased RIP3 expression was correlated with cancer development, including colon and lung cancers, nasopharyngeal carcinoma and non-Hodgkin lymphoma (120-122). The topoisomerase inhibitor SN38, an active metabolite of irinotecan, was demonstrated to mediate cytotoxicity through the TNF/TNFR signaling pathway in a panel of colon cancer cells (123). SN38 also promoted the progression of necroptosis, inhibited cell proliferation and induced DNA damage accumulation (123). This suggested that the SN38-induced activation of RIP1 and subsequent necroptosis may exert the therapeutic efficacy on colorectal carcinoma (123). Furthermore, Xin et al (124) reported that degradation of suppressor of cytokine signaling 1, a key negative regulator of IFN- $\gamma$ signaling, was prevented by TNF through RIP1/RIP3 signaling. The authors suggested that necroptotic inhibition might be a novel strategy for the treatment of acute myeloid leukemia through the combination of RIP1/RIP3 inhibitor with IFN- $\gamma$. Recently, bufalin was demonstrated to increase the expression of necroptosis mediators RIP1/RIP3 and ROS, leading to poly(ADP-ribose) polymerase (PARP)-dependent tumor cell death and tumor growth inhibition in MCF-7 and MDA-MB-231 human breast cancer cells (125). The promising role of RIP1/RIP3-dependent necroptosis in cancer therapy warrants attention in future studies (Table III).

RIP1/RIP3-dependent necroptosis in metabolic diseases. Glucose and its metabolism have a crucial role in driving necroptosis4 (1). Larocca et al (126) found that hyperglycemia upregulated necroptosis and shifted from apoptosis to necroptosis, associated with increased expression of RIP1, RIP3 and MLKL proteins. Sequentially, levels of RIP1 and MLKL increased in cerebral tissue from hyperglycemic neonatal mice that underwent hypoxia-ischemia brain injury (127). Current studies have documented that 
Table III. Potential of RIP1/RIP3-regulated necroptosis in diseases therapy.

\begin{tabular}{|c|c|c|c|}
\hline Disease & Compound or treatment & Pathological mechanism & (Refs.) \\
\hline Atherosclerosis & PS-341 & Impairing macrophage necroptosis and inflammation & $(111-113)$ \\
\hline Myocardial ischemia & Nec-1 & Reducing the infarct size induced by necroptosis & $(114)$ \\
\hline Cardiac hypertrophy & Losartan & $\begin{array}{l}\text { Inhibiting the RIP1/RIP3-induced necroptosis of cardiac } \\
\text { cell injury }\end{array}$ & $(116)$ \\
\hline Hyperglycemia & Nec-1s & $\begin{array}{l}\text { High glucose promotes necroptosis and the expression } \\
\text { of RIP1, RIP3, and MLKL proteins }\end{array}$ & $(126-128)$ \\
\hline $\begin{array}{l}\text { Acetaminophen-mediated } \\
\text { liver injury }\end{array}$ & Nec-1 & $\begin{array}{l}\text { Inhibiting acetaminophen-induced hepatic JNK } \\
\text { phosphorylation and mitochondrial Bax translocation }\end{array}$ & $(131)$ \\
\hline $\begin{array}{l}\text { Concanavalin A-induced } \\
\text { autoimmune hepatitis }\end{array}$ & Nec-1 or RIP3 $3^{-/-}$ & Inhibiting the necroptosis of hepatocytes & $(130)$ \\
\hline $\begin{array}{l}\text { Alcoholic fatty liver } \\
\text { disease }\end{array}$ & $\mathrm{RIP}^{-/-}$ & $\begin{array}{l}\text { Mice lacking RIP3 were protected from ethanol-induced } \\
\text { steatosis, hepatocyte injury, and expression of } \\
\text { proinflammatory cytokines }\end{array}$ & $(134)$ \\
\hline $\begin{array}{l}\text { Nonalcoholic fatty liver } \\
\text { disease }\end{array}$ & $\mathrm{RIP}^{-/-}$ & $\begin{array}{l}\text { Attenuating choline-deficient diet-induced liver injury, } \\
\text { steatosis, inflammation, fibrosis and oxidative stress }\end{array}$ & $(135)$ \\
\hline $\begin{array}{l}\text { CCl4-induced liver } \\
\text { fibrosis }\end{array}$ & Melatonin & $\begin{array}{l}\text { Preventing liver fibrosis by inhibiting necroptosis-associated } \\
\text { inflammatory signaling }\end{array}$ & $(136)$ \\
\hline $\begin{array}{l}\text { Renal ischemia-reperfusion } \\
\text { injury }\end{array}$ & Nec-1, RIP3-/- & $\begin{array}{l}\text { Inhibiting the necroptosis of organ damage, independent } \\
\text { of the immune system }\end{array}$ & $(138)$ \\
\hline $\begin{array}{l}\text { Kidney inflammation, } \\
\text { interstitial fibrosis }\end{array}$ & Nec-1 & $\begin{array}{l}\text { Inhibiting the necroptosis of kidney injury induced by } \\
\text { unilateral ureteral obstruction }\end{array}$ & $(140)$ \\
\hline Colorectal carcinoma & $\begin{array}{l}\text { Topoisomerase inhibitor } \\
\text { SN38 (active metabolite } \\
\text { of irinotecan) }\end{array}$ & $\begin{array}{l}\text { Promoting RIP1-depended necroptosis of HT29 and } \\
\text { HCT116 cell lines }\end{array}$ & $(123)$ \\
\hline Acute myeloid leukemia & $\begin{array}{l}\text { Nec-1 combined with } \\
\text { interferon- } \gamma\end{array}$ & $\begin{array}{l}\text { Combination treatment inactivates RIP1/RIP3-mediated } \\
\text { necroptotic signaling }\end{array}$ & $(124)$ \\
\hline Breast cancer & Bufalin & $\begin{array}{l}\text { Increasing the necroptosis mediators RIP1/RIP3 and } \\
\text { reactive oxygen species in MCF- } 7 \text { and MDA-MB-231 } \\
\text { human breast cancer cells }\end{array}$ & $(125)$ \\
\hline Retinal detachment & Nec-1, RIP3-- & Preventing necroptosis and reducing oxidative stress & $(142)$ \\
\hline Retinitis pigmentosa & $\mathrm{RIP}^{-/-}$ & Necroptosis promotes cone photoreceptor degeneration & $(143)$ \\
\hline $\begin{array}{l}\text { Amyotrophic lateral } \\
\text { sclerosis (induced by } \\
\text { optineurin deficiency) }\end{array}$ & Nec-1s & $\begin{array}{l}\text { Necroptosis and inflammation exacerbate disease } \\
\text { progression }\end{array}$ & $(147)$ \\
\hline Hyperuricemia & $\mathrm{RIP}^{-/-}$ & $\begin{array}{l}\text { Reducing pro-inflammatory cytokines and necroptosis } \\
\text { of kidney cells }\end{array}$ & $(128)$ \\
\hline Donor organ injury & Nec-1, RIP3 ${ }^{-/-}$ & Improving renal function & $(149)$ \\
\hline $\begin{array}{l}\text { Paraquat-induced cardiac } \\
\text { contractile dysfunction }\end{array}$ & Nec-1 & $\begin{array}{l}\text { Downregulating the RIP1/RIP3/MLKL signaling pathway } \\
\text { and preventing cardiac contractile dysfunction }\end{array}$ & $(117)$ \\
\hline Toxic epidermal necrolysis & Dabrafenib & Preventing RIP3-mediated necroptosis & $(150)$ \\
\hline
\end{tabular}

RIP, receptor-interacting serine/threonine kinase; Nec, necrostatin-1; Nec-1s, Nec-1 stable.

the intensity of necroptosis is closely associated with high glucose levels.

Hyperuricemia (HU) is closely related to metabolic syndrome. Wang et al (128) demonstrated that RIP3 was strongly expressed in mice with HU, whereas RIP3 deficiency attenuated HU symptoms. Using RIP3-knockout mice, various effects were observed following HU compared with RIP wild-type mice, namely downregulation of circulating and kidney pro-inflammatory cytokines (IL-1 $\beta$, TNF- $\alpha$ and IL-6), a decrease of FADD, cleaved caspase-8/-3 and PARP expression levels, and a decrease in TUNEL apoptotic staining in renal samples (128). These results suggested that RIP3 may have a crucial role in HU, and it may serve as a novel target for future therapeutic strategies (Table III). 
RIPI/RIP3-dependent necroptosis in liver injury. The death of hepatocytes initiates and aggravates chronic inflammation and fibrosis during liver injury, ultimately leading to liver cirrhosis and hepatocellular carcinoma. Increasing evidence indicates that necroptosis has a key role in acute liver injury and chronic liver injury (129). Deutsch et al (130) indicated that RIP1 and RIP3 have different roles in drug-induced or immunological acute liver injuries. In Concanavalin A (ConA)-induced autoimmune hepatitis, RIP3 deletion delayed hepatic injury, while RIP1 inhibition markedly exacerbated ConA-induced hepatitis (130). Conversely, in acetaminophen (APAP)-mediated liver injury, blockade of RIP1 or RIP3 ameliorated APAP toxicity (130). Zhang et al (131) demonstrated that RIP1 was strongly expressed and promoted acute liver failure in mice treated with APAP (300 mg/kg, intraperitoneally injected). Further analysis demonstrated that Nec-1, the inhibitor of RIP1, significantly inhibited APAP-induced hepatic JNK phosphorylation and mitochondrial Bax translocation (131). Using the APAP model in RIP3 ${ }^{--}$mice, Ramachandran et al (132) found that RIP3 knockout significantly reduced hepatotoxicity after $6 \mathrm{~h}$ of APAP treatment $(200-300 \mathrm{mg} / \mathrm{kg})$, while the protective effect of RIP3 knockout on the liver was not obvious after $24 \mathrm{~h}$ of APAP treatment.

Chronic liver injury usually includes alcoholic fatty liver disease (AELD), nonalcoholic fatty liver disease (NAFLD), liver fibrosis and cirrhosis. It has been reported that the expression of RIP3 in the liver tissue of patients with AFLD is abnormally elevated, and a series of pathological changes, such as hepatocyte lipid accumulation and elevated transaminase, are observed in the liver $(133,134)$. Additionally, Afonso et al $(135)$ reported that the expression of RIP3 and phosphorylated MLKL was increased in the liver tissue of patients with NAFLD, while RIP3 knockout significantly reduced the steatosis and inflammatory response in mice with methionine-choline diet. Choi et al (136) found that melatonin reduced the expression of RIP1, RIP3 and MLKL in rat fibrotic liver induced by $\mathrm{CCl}_{4}$, and inhibited the expression of high-mobility group box 1 (HMGB1) and IL-1 $\alpha$. This suggested that melatonin can alleviate liver fibrosis by inhibiting the inflammatory signaling associated with programmed necrosis (136). Further studies are required to fully elucidate the role of RIP1/RIP3-dependent necroptosis in liver injury (Table III).

RIPI/RIP3-dependent necroptosis in kidney injury. Increasing evidence has demonstrated that necroptosis has an important role in the pathogenesis of multiple types of kidney injury. Linkermann et al (137) first determined the presence of necroptosis in a murine model of renal ischemia-reperfusion injury (IRI). The detection of RIP1 and RIP3 in whole-kidney lysates and freshly isolated murine proximal tubules revealed the contribution of necroptosis in renal injury (137). A subsequent study demonstrated that, in a mouse model of IRI, necroptosis lead to primary organ damage, and RIP3-knockout mice were protected from IRI (138). Another study used MLKL-knockout mice to investigate the role of necroptosis in acute kidney injury (139). Their results revealed the indispensable role of MLKL in the necroptotic pathway (139). Additionally, Xiao et al (140) reported that the effect of necroptosis and the RIP1/RIP3/MLKL signaling pathway in renal inflammation and interstitial fibrosis was associated with primitive tubulointerstitial injury. Inhibition of necroptosis reduced the inflammatory response and interstitial fibrosis in renal tissues (140). Therefore, the signaling pathways and the main regulators of necroptosis may serve as potential candidates for therapeutic strategies in kidney injury (Table III).

RIPI/RIP3-dependent necroptosis in ocular disease. Apoptosis was previously demonstrated to be a significant form of cell loss in photoreceptor death, but RIP-mediated necrosis was recently discovered to be a crucial mode of photoreceptor cell loss in an experimental model of retinal detachment (141). Expression of RIP3 undergoes a 10-fold increase after retinal detachment (142). Nevertheless, Nec-1 or RIP3 deficiency substantially prevent necroptosis and reduce oxidative stress of apoptosis-inducing factor (142). Additionally, cone photoreceptor death in retinitis pigmentosa (RP) is widely considered as a necroptotic mechanism, while rod photoreceptor death is characterized by apoptotic features (143). Murakami et al (144) reported that RIP3 expression was elevated in rd10 mouse retinas in the cone phase, but not in rod degeneration, and thus suggested that RIP3 may be a potential target in protecting cone photoreceptors. On the other hand, Sato et al (145) found that RIP1/RIP3 accelerated both cone and rod photoreceptor degeneration in interphotoreceptor retinoid-binding protein $(\mathrm{Irbp})^{-/-}$mice. It is worth noting that Irbp deficiency displays severe early and progressive photoreceptor degeneration. Based on these studies, RIP1/RIP3 may be regarded as a potential therapeutic target to prevent or delay photoreceptor degeneration in patients with RP.

In an animal model of retinal detachment (RD), cleaved IL-1 $\beta$ was reported in infiltrated macrophages undergoing RIP3-dependent necroptosis, rather than dying photoreceptors (146). In addition, Ito et al (147) suggested a direct connection between amyotrophic lateral sclerosis induced by optineurin deficiency and RIP1-regulated necroptosis and inflammation. Because it promotes both inflammation and cell death, RIP1/RIP3 may be a common mediator of human degenerative diseases characterized by axonal degeneration (Table III).

Other properties of RIP1/RIP3-dependent necroptosis. Donor organ injury is invariably mentioned in transplantation, due to immune responses related to IRI and alloimmune rejection (148). Lau et al (149) reported that in caspase-inhibited tubular epithelial cells (TECs), necroptosis was triggered in vitro, following inhibition by $\mathrm{Nec}-1$ or RIP3 ${ }^{-1-}$ TEC. Following transplantation, recipients receiving RIP3 ${ }^{-/}$kidneys had longer survival and improved renal function (149). These results suggested that inhibition of RIP3-dependent necroptosis and inflammatory injury in donor organs may provide clinical benefit. Toxic epidermal necrolysis (TEN) is a severe adverse drug reaction with a high mortality rate (150). Kim et al (151) detected upregulated expression of RIP3 and elevated phosphorylation of MLKL in skin sections from patients with TEN. Dabrafenib notably prevented RIP3-mediated MLKL phosphorylation and decreased necroptosis, by inhibiting RIP3 in a TEN model (151). Based on these findings, it can be speculated that RIP may represent a potential target for treatment of TEN. Table III presents a list of existing studies on the role of RIP1/RIP3-mediated necroptosis in disease. 


\section{Conclusion and perspectives}

It is well-known that necroptosis, a physiologically relevant form of cell death, is involved in pathological cell death resulting from IRI. RIP1/RIP3 is a key cascade involved in necroptosis, which is regulated by caspase activation and ubiquitination. RIP1 regulates cell death and survival, while RIP3 mediates apoptosis and necroptosis. Both TLR and virus-mediated activation are recognized or identified by specific receptors or sensors placed either inside or on the surface of cells. RIP1/RIP3 mediates the initiation of the necroptotic response to different stimuli. Following ligand binding and receptor activation, RIP3 enters complex II via interaction with RIP1, which then activates MLKL participation in inflammation, immune response, embryonic development and metabolic abnormality.

In conclusion, an improved understanding of the molecular events regulating necroptotic cell death would be extremely beneficial for disease therapy, as these mechanisms are implicated in a variety of human illnesses. Further research in this area can be expected to provide promising opportunities regarding therapeutic exploitation of cell death programs. Due to its crucial roles in organ growth and tumor cell proliferation, RIP1/RIP3 may be a key potential therapeutic strategy in multiple severe diseases. Therefore, by using small molecules that specifically target necroptosis, it may be possible to alleviate symptoms and prolong the lives of patients. In coming years, further research on this alternative cell death pathway may include identification of additional RIP1 and RIP3 substrates. RIP3 appears to be the foremost promoter of necroptosis. In the future, studies exploiting RIP3 inhibitors may provide crucial insight into the diagnosis and treatment of necroptosis-associated diseases.

\section{Acknowledgements}

Not applicable.

\section{Funding}

This study was sponsored by the National Science Foundation of China (grant no 81802504), the Sichuan National Science Research Funding (grant no. 2018JY0645), Sichuan Health and Family Planning Commission Funding (grant no. 16ZD0253), Chengdu National Science Research Funding (grant no. 2018-YFYF-00146-SN), and funding from the Sichuan Scientific Research Grant for Returned Overseas Chinese Scholars for Dr Yi Wang. This study was also supported by the National Key Research and Development Plan of China (grant no. 2017YFC0113901), the Key Research and Development Plan of Sichuan Science and Technology Bureau (grant no. 2019YFS0278), the Health Care for government officials of Sichuan Province and the Sichuan Health and Family Planning Commission Funding (grant no. 120094) for Dr Yuping Liu.

\section{Availability of data and materials}

The datasets used and/or analyzed during the present study are available from the corresponding author on reasonable request.

\section{Authors' contributions}

YW, RT and YL conceived and designed the review. DZ, TLiu, TLei, SD and LG wrote the manuscript. TLei, DQ and CL prepared the figures. YW, RT and YL reviewed and edited the manuscript. All authors read and approved the final manuscript, and agree to be accountable for all aspects of the research in ensuring that the accuracy or integrity of any part of the work are appropriately investigated and resolved.

\section{Ethics approval and consent to participate}

Not applicable.

\section{Patient consent for publication}

Not applicable.

\section{Competing interests}

The authors declare that they have no competing interests.

\section{References}

1. Vandenabeele P, Galluzzi L, Vanden Berghe T and Kroemer G: Molecular mechanisms of necroptosis: An ordered cellular explosion. Nat Rev Mol Cell Biol 11: 700-714, 2010.

2. Degterev A, Huang Z, Boyce M, Jagtap P, Mizushima N, Cuny GD, Mitchison TJ, Moskowitz MA and Yuan J: Chemical inhibitor of nonapoptotic cell death with therapeutic potential for ischemic brain injury. Nat Chem Biol 1: 112-119, 2005.

3. Christofferson DE and Yuan J: Necroptosis as an alternative form of programmed cell death. Curr Opin Cell Biol 22: 263-268, 2010.

4. Ashkenazi A and Salvesen G: Regulated cell death: Signaling and mechanisms. Annu Rev Cell \& Dev Biol 30: 337-356, 2014.

5. Zhang YY and Liu H: Connections between various trigger factors and the RIP1/RIP3 signaling pathway involved in necroptosis. Asian Pac J Cancer Prev 14: 7069-7074, 2013.

6. Mason AR, Elia LP and Finkbeiner S: The receptor-interacting serine/threonine protein kinase 1 (RIPK1) regulates progranulin levels. J Biol Chem 292: 3262-3272, 2017.

7. Stanger BZ, Leder P, Lee TH, Kim E and Seed B: RIP: A novel protein containing a death domain that interacts with Fas/APO-1 (CD95) in yeast and causes cell death. Cell 81: 513-523, 1995.

8. Sun X, Lee J, Navas T, Baldwin DT, Stewart TA and Dixit VM: RIP3, a novel apoptosis-inducing kinase. J Biol Chem 274: 16871-16875, 1999.

9. Newton K: RIPK1 and RIPK3: Critical regulators of inflammation and cell death. Trends Cell Biol 25: 347-353, 2015.

10. Cho YS, Challa S, Moquin D, Genga R, Ray TD, Guildford M and Chan FK: Phosphorylation-driven assembly of the RIP1-RIP3 complex regulates programmed necrosis and virus-induced inflammation. Cell 137: 1112-1123, 2009.

11. Kaiser WJ, Upton JW, Long AB, Livingston-Rosanoff D, Daley-Bauer LP, Hakem R, Caspary T and Mocarski ES: RIP3 mediates the embryonic lethality of caspase-8-deficient mice. Nature 471: 368-372, 2011.

12. Zhou W and Yuan J: Necroptosis in health and diseases. Semin Cell Dev Biol 35: 14-23, 2014.

13. Vandenabeele P, Declercq W, Van Herreweghe F and Vanden Berghe T: The role of the kinases RIP1 and RIP3 in TNF-induced necrosis. Sci Signal 3: re4, 2010.

14. Wu XN, Yang ZH, Wang XK, Zhang Y, Wan H, Song Y, Chen X, Shao J and Han J: Distinct roles of RIP1-RIP3 hetero- and RIP3-RIP3 homo-interaction in mediating necroptosis. Cell Death Differ 21: 1709-1720, 2014.

15. Wen L, Zhuang L, Luo X and Wei P: TL1A-induced NF-kappaB activation and c-IAP2 production prevent DR3-mediated apoptosis in TF-1 cells. J Biol Chem 278: 39251-39258, 2003. 
16. Ahmad M, Srinivasula SM, Wang L, Talanian RV, Litwack G, Fernandes-Alnemri T and Alnemri ES: CRADD, a novel human apoptotic adaptor molecule for caspase-2, and FasL/tumor necrosis factor receptor-interacting protein RIP. Cancer Res 57: 615-619, 1997.

17. Festjens N, Vanden BT, Cornelis S and Vandenabeele P: RIP1, a kinase on the crossroads of a cell's decision to live or die. Cell Death Differ 14: 400-410, 2007.

18. Newton K, Sun X and Dixit VM: Kinase RIP3 is dispensable for normal NF-kappa Bs, signaling by the B-cell and T-cell receptors, tumor necrosis factor receptor 1 , and Toll-like receptors 2 and 4. Mol Cell Biol 24: 1464-1469, 2004.

19. Sun X, Yin J, Starovasnik MA, Fairbrother WJ and Dixit VM: Identification of a novel homotypic interaction motif required for the phosphorylation of receptor-interacting protein (RIP) by RIP3. J Biol Chem 277: 9505-9511, 2002.

20. Luedde M, Lutz M, Carter N, Sosna J, Jacoby C, Vucur M, Gautheron J, Roderburg C, Brg N, Reisinger F, et al: RIP3, a kinase promoting necroptotic cell death, mediates adverse remodelling after myocardial infarction. Cardiovasc Res 103 . 206-216, 2014.

21. Günther C, Neumann H, Neurath MF and Becker C: Apoptosis, necrosis and necroptosis: Cell death regulation in the intestinal epithelium. Gut 62: 1062-1071, 2013.

22. Pasparakis M and Vandenabeele P: Necroptosis and its role in inflammation. Nature 517: 311-320, 2015.

23. Magnusson C and Vaux DL: Signalling by CD95 and TNF receptors: Not only life and death. Immunol Cell Biol 77: 41-46, 1999

24. Lan YH, Wu YC, Wu KW, Chung JG, Lu CC, Chen YL, Wu TS and Yang JS: Death receptor 5-mediated TNFR family signaling pathways modulate $\gamma$-humulene-induced apoptosis in human colorectal cancer HT29 cells. Oncol Rep 25: 419-424, 2011

25. Pan G, Bauer JH, Haridas V, Wang S, Liu D, Yu G, Vincenz C, Aggarwal BB, Ni J and Dixit VM: Identification and functional characterization of DR6, a novel death domain-containing TNF receptor. FEBS Lett 431: 351-356, 1998.

26. Andera L: Signaling activated by the death receptors of the TNFR family. Biomed Pap Med Fac Univ Palacky Olomouc Czech Repub 153: 173-180, 2009.

27. Yoshikawa M, Saitoh M, Katoh T, Seki T, Bigi SV, Shimizu Y, Ishii $\mathrm{T}$, Okai $\mathrm{T}$, Kuno $\mathrm{M}$, Hattori $\mathrm{H}$, et al: Discovery of 7-Oxo-2,4,5,7-tetrahydro-6 H-pyrazolo[3,4-c]pyridine derivatives as potent, orally available, and brain-penetrating receptor interacting protein 1 (RIP1) kinase inhibitors: Analysis of structure-kinetic relationships. J Med Chem 61: 2384-2409, 2018

28. Vanlangenakker N, Bertrand MJM, Bogaert P, Vandenabeele P and Berghe TV: TNF-induced necroptosis in L929 cells is tightly regulated by multiple TNFR1 complex I and II members. Cell Death Dis 2: e230, 2011.

29. Micheau O and Tschopp J: Induction of TNF receptor I-mediated apoptosis via two sequential signaling complexes. Cell 114: 181-190, 2003

30. Wong WW, Gentle IE, Nachbur U, Anderton H, Vaux DL and Silke J: RIPK1 is not essential for TNFR1-induced activation of NF-kappaB. Cell Death Differ 17: 482-487, 2010.

31. Mack C, Sickmann A, Lembo D and Brune W: Inhibition of proinflammatory and innate immune signaling pathways by a cytomegalovirus RIP1-interacting protein. Proc Natl Acad Sci USA 105: 3094-3099, 2008.

32. Wang L, Du F and Wang X: TNF-alpha induces two distinct caspase-8 activation pathways. Cell 133: 693-703, 2008.

33. Benetatos CA, Mitsuuchi Y, Burns JM, Neiman EM, Condon SM, Yu G, Seipel ME, Kapor GS, Laporte MG, Rippin SR, et al: Birinapant (TL32711), a bivalent SMAC mimetic, targets TRAF2-associated cIAPs, abrogates TNF-induced NF- $\kappa$ B activation, and is active in patient-derived xenograft models. Mol Can Ther 13: 867-879, 2014.

34. Hughes MA, Powley IR, Jukesjones R, Horn S, Feoktistova M, Fairall L, Schwabe JW, Leverkus M, Cain K, MacFarlane M, et al: Co-operative and hierarchical binding of c-FLIP and caspase-8: A unified model defines how c-FLIP isoforms differentially control cell fate. Mol Cell 61: 834-849, 2016.

35. Oberst A, Dillon CP, Weinlich R, McCormick LL, Fitzgerald P, Pop C, Hakem R, Salvesen GS and Green DR: Catalytic activity of the caspase-8-FLIPL complex inhibits RIPK3-dependent necrosis. Nature 471: 363-367, 2011.

36. Ikner A and Ashkenazi A: TWEAK induces apoptosis through a death-signaling complex comprising receptor-interacting protein 1 (RIP1), Fas-associated death domain (FADD), and caspase-8. J Biol Chem 286: 21546-21554, 2011
37. Lin Y, Devin A, Rodriguez Y and Liu Z: Cleavage of the death domain kinase RIP by Caspase- 8 prompts TNF-induced apoptosis. Genes Dev 13: 2514-2526, 1999.

38. Vanden BT, Linkermann A, Jouan-Lanhouet S, Walczak H and Vandenabeele P: Regulated necrosis: The expanding network of non-apoptotic cell death pathways. Nat Rev Mol Cell Biol 15: 135-147, 2014.

39. Li J, Mcquade T, Siemer AB, Napetschnig J, Moriwaki K, Hsiao YS, Damko E, Moquin D, Walz T, McDermott A, et al: The RIP1/RIP3 necrosome forms a functional amyloid signaling complex required for programmed necrosis. Cell 150: 339-350, 2012.

40. He S, Wang L, Miao L, Wang T, Du F, Zhao L and Wang X: Receptor interacting protein kinase-3 determines cellular necrotic response to TNF-alpha. Cell 137: 1100-1111, 2009.

41. Zhang Y, Su SS, Zhao S, Yang Z, Zhong CQ, Chen X, Cai Q, Yang $\mathrm{ZH}$, Huang D, Wu R and Han J: RIP1 autophosphorylation is promoted by mitochondrial ROS and is essential for RIP3 recruitment into necrosome. Nat Commun 8: 14329, 2017.

42. Moquin DM, Mcquade T and Chan FK: CYLD deubiquitinates RIP1 in the TNF $\alpha$-induced necrosome to facilitate kinase activation and programmed necrosis. PLoS One 8: e76841, 2013.

43. Sun L, Wang H, Wang Z, He S, Chen S, Liao D, Wang L, Yan J, Liu W, Lei X and Wang X: Mixed lineage kinase domain-like protein mediates necrosis signaling downstream of RIP3 kinase. Cell 148: 213-227, 2012.

44. Dondelinger Y, Declercq W, Montessuit S, Roelandt R, Goncalves A, Bruggeman I, Hulpiau P, Weber K, Sehon CA and Marquis RW: MLKL compromises plasma membrane integrity by binding to phosphatidylinositol phosphates. Cell Rep 7: 971-981, 2014.

45. Wang H, Sun L, Su L, Rizo J, Liu L, Wang LF, Wang FS and Wang X: Mixed lineage kinase domain-like protein MLKL causes necrotic membrane disruption upon phosphorylation by RIP3. Mol Cell 54: 133-146, 2014.

46. Kaiser WJ, Sridharan H, Huang C, Mandal P, Upton JW, Gough PJ, Sehon CA, Marquis RW, Bertin J and Mocarski ES: Toll-like receptor 3-mediated necrosis via TRIF, RIP3, and MLKL. J Biol Chem 288: 31268-31279, 2013.

47. He S, Liang Y, Shao F and Wang X: Toll-like receptors activate programmed necrosis in macrophages through a receptor-interacting kinase-3-mediated pathway. Proc Natl Acad Sci USA 108: 20054-20059, 2011.

48. Lu J: Regulation of necroptosis and autophagy in T cell homeostasis and function. University of California, Irvine, 2014.

49. Walsh CM: Grand challenges in cell death and survival: Apoptosis vs. necroptosis. Front Cell Dev Biol 2: 3, 2014.

50. Hoshino K, Takeuchi O, Kawai T, Sanjo H, Ogawa T, Takeda Y, Takeda K and Akira S: Cutting edge: Toll-like receptor 4 (TLR4)-deficient mice are hyporesponsive to lipopolysaccharide: Evidence for TLR4 as the Lps gene product. J Immunol 162: 3749-3752, 1999.

51. Takaki H, Shime H, Matsumoto M and Seya T: Tumor cell death by pattern-sensing of exogenous RNA: Tumor cell TLR3 directly induces necroptosis by poly(I:C) in vivo, independent of immune effector-mediated tumor shrinkage. Oncoimmunology 6: e1078968, 2015

52. Yamamoto M, Sato S, Hemmi H, Hoshino K, Kaisho T, Sanjo H, Takeuchi O, Sugiyama M, Okab M, Takeda K and Akira S: Role of adaptor TRIF in the MyD88-independent toll-like receptor signaling pathway. Science 301: 640-643, 2003.

53. Kawai T, Adachi O, Ogawa T, Takeda K and Akira S: Unresponsiveness of MyD88-deficient mice to endotoxin. Immunity 11: 115-122, 1999.

54. Hoebe K, Du X, Georgel P, Janssen E, Tabeta K, Kim SO, Goode J, Lin P, Mann N and Mudd S: Identification of Lps2 as a key transducer of MyD88-independent TIR signalling. Nature 424: 743-748, 2003.

55. Holler N, Zaru R, Micheau O, Thome M, Attinger A, Valitutti S, Bodmer JL, Schneider P, Seed B and Tschopp J: Fas triggers an alternative, caspase-8-independent cell death pathway using the kinase RIP as effector molecule. Nature Immunol 1: 489-495, 2000.

56. Geserick P, Hupe M, Moulin M, Wong WW, Feoktistova M, Kellert B, Gollnick H, Silke J and Leverkus M: Cellular IAPs inhibit a cryptic CD95-induced cell death by limiting RIP1 kinase recruitment. J Cell Biol 187: 1037-1054, 2009.

57. Robinson N, Mccomb S, Mulligan R, Dudani R, Krishnan L and Sad S: Type I interferon induces necroptosis in macrophages during infection with salmonella enterica serovar typhimurium. Nature Immunol 13: 954-962, 2012. 
58. Kaiser WJ, Upton JW and Mocarski ES: Viral modulation of programmed necrosis. Curr Opin Virol 3: 296-306, 2013.

59. Zhang Y, Chen X, Gueydan C and Han J: Plasma membrane changes during programmed cell deaths. Cell Res 28: 9-21,2018.

60. Orozco S, Yatim N, Werner MR, Tran H, Gunja SY, Tait SW, Albert ML, Green DR and Oberst A: RIPK1 both positively and negatively regulates RIPK3 oligomerization and necroptosis Cell Death Differ 21: 1511-1521, 2014.

61. Wajant $\mathrm{H}$ and Scheurich P: TNFR1-induced activation of the classical NF- $\kappa$ B pathway. FEBS J 278: 862-876, 2011.

62. Jaco I, Annibaldi A, Lalaoui N, Wilson R, Tenev T, Laurien L, Kim C, Jamal K, Wicky John S, Liccardi G, et al: MK2 phosphorylates RIPK1 to prevent TNF-induced cell death. Mol Cell 66: 698-710.e5, 2017.

63. Kearney CJ,Cullen SP,Danielle Cand Martin SJ: RIPK1 can function as an inhibitor rather than an initiator of RIPK3-dependent necroptosis. FEBS J 281: 4921-4934, 2015.

64. Schenk B and Fulda S: Reactive oxygen species regulate Smac mimetic/TNF $\alpha$-induced necroptotic signaling and cell death Oncogene 34: 5796-5806, 2015.

65. Zhang DW, Shao J, Lin J, Zhang N, Lu BJ, Lin SC, Dong MQ and Han J: RIP3, an energy metabolism regulator that switches TNF-induced cell death from apoptosis to necrosis. Science 325: 332-336, 2009.

66. Wen S, Wu X, Gao H, Yu J, Zhao W, Lu JJ, Wang J, Du G and Chen X: Cytosolic calcium mediates RIP1/RIP3 complex-dependent necroptosis through JNK activation and mitochondrial ROS production in human colon cancer cells. Free Radic Biol Med 108: 433-444, 2017.

67. Kearney CJ and Martin SJ: An inflammatory perspective on necroptosis. Mol Cell 65: 965-973, 2017.

68. Martin SJ: Cell death and inflammation: The case for IL-1 family cytokines as the canonical DAMPs of the immune system. FEBS J 283: 2599-2615, 2016.

69. Kono H and Rock KL: How dying cells alert the immune system to danger. Nat Rev Immunol 8: 279-289, 2008

70. Fan H, Liu F, Dong G, Ren D, Xu Y, Dou J, Wang T, Sun L and Hou Y: Activation-induced necroptosis contributes to B-cel lymphopenia in active systemic lupus erythematosus. Cell Death Dis 5: e1416, 2014.

71. Siegel RM: Caspases at the crossroads of immune-cell life and death. Nat Rev Immunol 6: 308-317, 2006.

72. Bell BD, Leverrier S, Weist BM, Newton RH, Arechiga AF, Luhrs KA, Morrissette NS and Walsh CM: FADD and caspase-8 control the outcome of autophagic signaling in proliferating T cells. Proc Natl Acad Sci USA 105: 16677-16682, 2009.

73. Lu JV and Walsh CM: Programmed necrosis and autophagy in immune function. Immunol Rev 249: 205-217, 2012.

74. O'Donnell JA, Lehman J, Roderick JE, Martinez-Marin D, Zelic M, Doran C, Hermance N, Lyle S, Pasparakis M, Fitzgerald KA, et al: Dendritic cell RIPK1 maintains immune homeostasis by preventing inflammation and autoimmunity. J Immunol 200: 737-748, 2018.

75. Giltiay NV, Chappell CP, Sun X, Kolhatkar N, Teal TH, Wiedeman AE, Kim J, Tanaka L, Buechler MB, Hamerman JA, et al: Overexpression of TLR7 promotes cell-intrinsic expansion and autoantibody production by transitional T1 B cells. J Exp Med 210: 2773-2789, 2013

76. Mina-Osorio P, LaStant J, Keirstead N, Whittard T, Ayala J, Stefanova S, Garrido R, Dimaano N, Hilton H, Giron M, et al Suppression of glomerulonephritis in lupus-prone NZB x NZW mice by RN486, a selective inhibitor of Bruton's tyrosine kinase. Arthritis Rheum 65: 2380-2391, 2013.

77. Biton S and Ashkenazi A: NEMO and RIP1 control cell fate in response to extensive DNA damage via TNF- $\alpha$ feedforward signaling. Cell 145: 92-103, 2011.

78. Xu C, Wu X, Zhang X, Xie Q, Fan C and Zhang H: Embryonic lethality and host immunity of relA-deficient mice are mediated by both apoptosis and necroptosis. J Immunol 200: 271-285, 2017.

79. Lu JV, Weist BM, van Raam BJ, Marro BS, Nguyen LV, Srinivas P, Bell BD, Luhrs KA, Lane TE, Salvesen GS and Walsh CM: Complementary roles of fas-associated death domain (FADD) and receptor interacting protein kinase-3 (RIPK3) in T-cell homeostasis and antiviral immunity. Proc Natl Acad Sci USA 108: 15312-15317, 2011

80.Zhang H, Zhou X, Mcquade T, Li J, Chan FK and Zhang J: Functional complementation between FADD and RIP1 in embryos and lymphocytes. Nature 471: 373-376, 2011.
81. Liu Y, Fan C, Zhang Y, Yu X, Wu X, Zhang X, Zhao Q, Zhang H, Xie Q, Li M, et al: RIP1 kinase activity-dependent roles in embryonic development of fadd-deficient mice. Cell Death Differ 24: 1459-1469, 2017.

82. Dillon CP, Oberst A, Weinlich R, Janke LJ, Kang TB Ben-Moshe T, Mak TW, Wallach D and Green DR: Survival function of the FADD-CASPASE-8-cFLIP(L) complex. Cell Rep 1: 401-407, 2012

83. Kaiser WJ, Daleybauer LP, Thapa RJ, Mandal P, Berger SB Huang C, Sundararajan A, Guo H, Roback L, Speck SH, et al: RIP1 suppresses innate immune necrotic as well as apoptotic cell death during mammalian parturition. Proc Natl Acad Sci USA 111: 7753-7758, 2014.

84. Dillon CP, Weinlich R, Rodriguez DA, Cripps JG, Quarato G, Gurung P, Verbist KC, Brewer TL, Llambi F, Gong YN, et al: RIPK 1 blocks early postnatal lethality mediated by caspase- 8 and RIPK3. Cell 157: 1189-1202, 2014.

85. Dowling JP, Nair A and Zhang J: A novel function of RIP1 in postnatal development and immune homeostasis by protecting against RIP3-dependent necroptosis and FADD-mediated apoptosis. Front Cell Dev Biol 3: 12, 2015.

86. Degterev A, Hitomi J, Germscheid M, Ch'en IL, Korkina O, Teng X, Abbott D, Cuny GD, Yuan C, Wagner G, et al: Identification of RIP1 kinase as a specific cellular target of necrostatins. Nat Chem Biol 4: 313-321, 2008.

87. Takahashi N, Duprez L, Grootjans S, Cauwels A, Nerinckx W, DuHadaway JB, Goossens V, Roelandt R, Van Hauwermeiren F, Libert C, et al: Necrostatin-1 analogues: Critical issues on the specificity, activity andin vivouse in experimental disease models. Cell Death Dis 3: e437, 2012.

88. Harris PA, Berger SB, Jeong JU, Nagilla R, Bandyopadhyay D, Campobasso N, Capriotti CA, Cox JA, Dare L, Dong X, et al: Discovery of a first-in-class receptor interacting protein 1 (RIP1) kinase specific clinical candidate (GSK2982772) for the treatment of inflammatory diseases. J Med Chem 60: 1247-1261, 2017.

89. Ren Y, Su Y, Sun L, He S, Meng L, Liao D, Liu X, Ma Y, Liu C $\mathrm{Li} \mathrm{S}$, et al: Discovery of a highly potent, selective, and metabolically stable inhibitor of receptor-interacting protein 1 (RIP1) for the treatment of systemic inflammatory response syndrome. J Med Chem 60: 972-986, 2017.

90. Martens S, Goossens V, Devisscher L, Hofmans S, Claeys P, Vuylsteke M, Takahashi N, Augustyns K and Vandenabeele P: RIPK1-dependent cell death: A novel target of the Aurora kinase inhibitor Tozasertib (VX-680). Cell Death Dis 9: 211, 2018.

91. Fauster A, Rebsamen M, Huber KVM, Bigenzahn JW, Stukalov A, Lardeau CH, Scorzoni S, Bruckner M, Gridling M, Parapatics K, et al: A cellular screen identifies ponatinib and pazopanib as inhibitors of necroptosis. Cell Death Dis 6: e1767, 2015.

92. Alcalá AM and Flaherty KT: BRAF inhibitors for the treatment of metastatic melanoma: Clinical trials and mechanisms of resistance. Clin Cancer Res 18: 33-39, 2012.

93. Li JX, Feng JM, Wang Y, Li XH, Chen XX, Su Y, Shen YY, Chen Y, Xiong B, Yang CH, et al: The B-RafV600E inhibitor dabrafenib selectivelyinhibits RIP3 and alleviates acetaminophen-induced liver injury. Cell Death Dis 5: e1278, 2014.

94. Cruz SA, Qin Z, Afr S and Chen HH: Dabrafenib, an inhibitor of RIP3 kinase-dependent necroptosis, reduces ischemic brain injury. Neural Regen Res 13: 252-256, 2018.

95. Omoto S, Guo H, Talekar GR, Roback L, Kaiser WJ and Mocarski ES: Suppression of RIP3-dependent necroptosis by human cytomegalovirus. J Biol Chem 290: 11635-11648, 2015.

96. Liu J, Mil AV, Vrijsen K, Zhao J, Gao L, Metz CH, Goumans MJ, Doevendans PA and Sluijter JP: MicroRNA-155 prevents necrotic cell death in human cardiomyocyte progenitor cells via targeting RIP1. J Cell Mol Med 15: 1474-1482, 2011.

97. Dhingra R, Lin J and Kirshenbaum LA: Disruption of RIP1-FADD complexes by microRNA-103/107 provokes necrotic cardiac cell death. Circ Res 117: 314-316, 2015.

98. Wang JX, Zhang XJ, Li Q, Wang K, Wang Y, Jiao JQ, Feng C, Teng S, Zhou LY, Gong Y, et al: MicroRNA-103/107 regulate programmed necrosis and myocardial ischemia/reperfusion injury through targeting FADD. Circ Res 117: 352-363, 2015.

99. Wo L, Lu D and Gu X: Knockdown of miR-182 promotes apoptosis via regulating RIP1 deubiquitination in TNF- $\alpha$-treated triple-negative breast cancer cells. Tumour Biol 37: 13733-13742, 2016.

100.Zheng M, Wu Z, Wu A, Huang Z, He N and Xie X: MiR-145 promotes TNF- $\alpha$-induced apoptosis by facilitating the formation of RIP1-FADDcaspase-8 complex in triple-negative breast cancer. Tumor Biol 37: 8599-8607, 2016. 
101. Li D, Xu T, Cao Y, Wang H, Li L, Chen S, Wang X and Shen Z: A cytosolic heat shock protein 90 and cochaperone CDC37 complex is required for RIP3 activation during necroptosis. Proc Natl Acad Sci USA 112: 5017-5022, 2015.

102. Li D, Li C, Li L, Chen S, Wang L, Li Q, Wang X, Lei X and Shen Z: Natural product kongensin a is a non-canonical HSP90 inhibitor that blocks RIP3-dependent necroptosis. Cell Chem Biol 23: 257-266, 2016.

103. Jacobsen AV, Lowes KN, Tanzer MC, Lucet IS, Hildebrand JM, Petrie EJ, van Delft MF, Liu Z, Conos SA, Zhang JG, et al: HSP90 activity is required for MLKL oligomerisation and membrane translocation and the induction of necroptotic cell death. Cell Death Dis 7: e2051, 2016.

104. Zhao XM, Chen Z, Zhao JB, Zhang PP, Pu YF, Jiang SH, Hou JJ, Cui YM, Jia XL and Zhang SQ: Hsp90 modulates the stability of MLKL and is required for TNF-induced necroptosis. Cell Death Dis 7: e2089, 2016.

105. Park SY, Shim JH, Chae JI and Cho YS: Heat shock protein 90 inhibitor regulates necroptotic cell death via down-regulation of receptor interacting proteins. Pharmazie 70: 193-198, 2015.

106. Declercq W, Vanden BT and Vandenabeele P: RIP kinases at the crossroads of cell death and survival. Cell 138: 229-232, 2009.

107. Chan FK, Luz NF and Moriwaki K: Programmed necrosis in the cross talk of cell death and inflammation. Annu Rev Immunol 33: 79-106, 2015.

108. Ariana A: Dissection of TLR4-Induced Necroptosis Using Specific Inhibitors of Endocytosis and P38 MAPK. In: Department of Biochemistry, Microbiology and Immunology University of Ottawa, Ottawa, Canada, 2017.

109. Upton JW, Kaiser WJ and Mocarski ES: DAI complexes with RIP3 to mediate virus-induced programmed necrosis that is targeted by murine cytomegalovirus vIRA. Cell Host Microbe 11: 290-297, 2012.

110. Gupta K, Phan N, Wang Q and Liu B: Necroptosis in cardiovascular disease-a new therapeutic target. J Mol Cell Cardiol 118: 26-35, 2018.

111. Lin J, Li H, Yang M, Ren J, Huang Z, Han F, Huang J, Ma J, Zhang D, Zhang Z, et al: A role of RIP3-mediated macrophage necrosis in atherosclerosis development. Cell Rep 3: 200-210, 2013

112. Meng L, Jin W and Wang X: RIP3-mediated necrotic cell death accelerates systematic inflammation and mortality. Proc Natl Acad Sci USA 112: 11007-11012, 2015.

113. Zhang Y, Cheng J, Zhang J, Wu X, Chen F, Ren X, Wang Y, Li Q and Li Y: Proteasome inhibitor PS-341 limits macrophage necroptosis by promoting cIAPs-mediated inhibition of RIP1 and RIP3 activation. Biochem Biophys Res Commun 477: 761-767, 2016

114. Oerlemans MI, Liu J, Arslan F, den Ouden K, van Middelaar BJ, Doevendans PA and Sluijter JP: Inhibition of RIP1-dependent necrosis prevents adverse cardiac remodeling after myocardial ischemia-reperfusion in vivo. Basic Res Cardiol 107: 270, 2012.

115. Zhu P, Hu S, Jin Q, Li D, Tian F, Toan S, Li Y, Zhou H and Chen Y: Ripk3 promotes ER stress-induced necroptosis in cardiac IR injury: A mechanism involving calcium overload/XO/ROS/mPTP pathway. Redox Biol 16: 157-168, 2018.

116. Zhao M, Qin Y, Lu L, Tang X, Wu W, Fu H and Liu X: Preliminary study of necroptosis in cardiac hypertrophy induced by pressure overload. Sheng Wu Yi Xue Gong Cheng Xue Za Zhi 32: 618-623, 2015 (In Chinese).

117. Zhang L, Feng Q and Wang T: Necrostatin-1 protects against paraquat-induced cardiac contractile dysfunction via RIP1-RIP3-MLKL-dependent necroptosis pathway. Cardiovasc Toxicol 18: 346-355, 2018.

118. Meng MB, Wang HH, Cui YL, Wu ZQ, Shi YY, Zaorsky NG Deng L, Yuan ZY, Lu Y and Wang P: Necroptosis in tumorigenesis, activation of anti-tumor immunity, and cancer therapy. Oncotarget 7: 57391-57413, 2016.

119. Chen D, Yu J and Zhang L: Necroptosis: An alternative cell death program defending against cancer. Biochim Biophys Acta 1865: 228-236, 2016.

120. Yang Y, Hu W, Feng S, Ma J and Wu M: RIP3 beta and RIP3 gamma, two novel splice variants of receptor-interacting protein 3 (RIP3), downregulate RIP3-induced apoptosis. Biochem Biophys Res Commun 332: 181-187, 2005.

121. Kasof GM, Prosser JC, Liu D, Lorenzi MV and Gomes BC: The RIP-like kinase, RIP3, induces apoptosis and NF-kappaB nuclear translocation and localizes to mitochondria. FEBS Lett 473: 285-291, 2000.
122. Wu W, Liu P and Li J: Necroptosis: An emerging form of programmed cell death. Crit Rev Oncol Hematol 82: 249-258, 2012.

123. Cabal-Hierro L and O'Dwyer PJ: TNF signaling through RIP1 kinase enhances SN38-induced death in colon adenocarcinoma. Mol Cancer Res 15: 395-404, 2017

124. Xin J, You D, Breslin P, Li J, Zhang J, Wei W, Cannova J, Volk A, Gutierrez R, Xiao Y, et al: Sensitizing acute myeloid leukemia cells to induced differentiation by inhibiting the RIP1/RIP3 pathway. Leukemia 124: 1154-1165, 2017.

125. Li Y, Liu X, Gong P and Tian X: Bufalin inhibits human breast cancer tumorigenesis by inducing cell death through the ROS-Mediated RIP1/RIP3/PARP-1 pathways. Carcinogenesis 39: 700-707, 2018.

126. Larocca TJ, Sosunov SA, Shakerley NL, Ten VS and Ratner AJ: Hyperglycemic conditions prime cells for RIP1-dependent necroptosis. J Biol Chem 291: 13753-13761, 2016.

127. Mccaig WD, Patel PS, Sosunov SA, Shakerley NL, Smiraglia TA, Craft MM, Walker KM, Deragon MA, Ten VS and LaRocca TJ: Hyperglycemia potentiates a shift from apoptosis to RIP1-dependent necroptosis. Cell Death Discov 4: 55, 2018.

128. Wang K, Hu L and Chen JK: RIP3-deficience attenuates potassium oxonate-induced hyperuricemia and kidney injury. Biomed Pharmacother 101: 617-626, 2018.

129. Dara L, Liu ZX and Kaplowitz N: Questions and controversies: The role of necroptosis in liver disease. Cell Death Discov 2: $16089,2016$.

130. Deutsch M, Graffeo CS, Rokosh R, Pansari M, Ochi A, Levie EM, Van Heerden E, Tippens DM, Tippens DM, Greco S, et al: Divergent effects of RIP1 or RIP3 blockade in murine models of acute liver injury. Cell Death Dis 6: e1759, 2015.

131. Zhang YF, He W, Zhang C, Liu XJ, Lu Y, Wang H, Zhang ZH, Chen $\mathrm{X}$ and $\mathrm{Xu}$ DX: Role of receptor interacting protein (RIP)1 on apoptosis-inducing factor-mediated necroptosis during acetaminophen-evoked acute liver failure in mice. Toxicol Lett 225: 445-453, 2014

132. Ramachandran A, McGill MR, Xie Y, Ni HM, Ding WX and Jaeschke H: Receptor interacting protein kinase 3 is a critical early mediator of acetaminophen-induced hepatocyte necrosis in mice. Hepatology 58: 2099-2108, 2013.

133. Roychowdhury S, McMullen MR, Pisano SG, Liu X and Nagy LE: Absence of receptor interacting protein kinase 3 prevents ethanol-induced liver injury. Hepatology 57: 1773-1783, 2013.

134. Wang S, Ni HM, Dorko K, Kumer SC, Schmitt TM, Nawabi A, Komatsu M, Huang Hand Ding WX: Increased hepatic receptor interacting protein kinase 3 expression due to impaired proteasomal functions contributes to alcohol-induced steatosis and liver injury. Oncotarget 7: 17681-17698, 2016.

135. Afonso MB, Rodrigues PM, Carvalho T, Caridade M, Borralho P, Cortez-Pinto H, Castro RE and Rodrigues CM: Necroptosis is a key pathogenic event in human and experimental murine models of non-alcoholic steatohepatitis. Clin Sci (Lond) 129: 721-739, 2015.

136. Choi HS, Kang JW and Lee SM: Melatonin attenuates carbon tetrachloride-induced liver fibrosis via inhibition of necroptosis. Transl Res 166: 292-303, 2015.

137. Linkermann A, Brasen JH, Himmerkus N, Liu S, Huber TB, Kunzendorf U and Krautwald S: Rip1 (receptor-interacting protein kinase 1) mediates necroptosis and contributes to renal ischemia/reperfusion injury. Kidney Int 81: 751-761, 2012.

138. Linkermann A, Brasen JH, Darding M, Jin MK, Sanz AB, Heller JO, De Zen F, Weinlich R, Ortiz A, Walczak H, et al: Two independent pathways of regulated necrosis mediate ischemia-reperfusion injury. Proc Natl Acad Sci USA 110: 12024-12029, 2013.

139. Xu Y, Ma H, Shao J, Wu J, Zhou L, Zhang Z, Wang Y, Huang Z, Ren J, Liu S, et al: A role for tubular necroptosis in cisplatin-induced AKI. J Am Soc Nephrol 26: 2647-2658, 2015.

140. Xiao X, Du C, Yan Z, Shi Y, Duan H and Ren Y: Inhibition of necroptosis attenuates kidney inflammation and interstitial fibrosis induced by unilateral ureteral obstruction. Am J Nephrol 46: 131-138, 2017.

141. Murakami Y, Trichonas G, Thanos A, Mantopulos D, Morizane Y, Kayama M, Hisatomi T, Miller J and Vavvas D: The role of RIP-mediated necrosis and autophagy in photoreceptor death after retinal detachment. Invest Ophthalmol Vis Sci 52: 6588, 2011. 
142. Trichonas G, Murakami Y, Thanos A, Morizane Y, Kayama M, Debouck CM, Hisatomi T, Miller JW and Vavvas DG: Receptor interacting protein kinases mediate retinal detachment-induced photoreceptor necrosis and compensate for inhibition of apoptosis. Proc Natl Acad Sci USA 107: 21695-21700, 2010.

143. Murakami Y, Ikeda Y, Nakatake S, Miller JW, Vavvas DG, Sonoda KH and Ishibashi T: Necrotic cone photoreceptor cell death in retinitis pigmentosa. Cell Death Dis 6: e2038,2015.

144. Murakami Y, Matsumoto H, Roh M, Suzuki J, Hisatomi T, Ikeda Y, Miller JW and Vavvas DG: Receptor interacting protein kinase mediates necrotic cone but not rod cell death in a mouse model of inherited degeneration. Proc Natl Acad Sci USA 109: 14598-14603, 2012.

145. Sato K, Li S, Gordon WC, He J, Liou GI, Hill JM, Travis GH, Bazan NGand Jin M:Receptorinteracting proteinkinase-mediated necrosis contributes to cone and rod photoreceptor degeneration in the retina lacking interphotoreceptor retinoid-binding protein. J Neurosci 33: 17458-17468, 2013.

146. Kataoka K, Matsumoto H, Kaneko H, Notomi S, Takeuchi K, Sweigard JH, Atik A, Murakami Y, Connor KM, Terasaki H, et al: Macrophage- and RIP3-dependent inflammasome activation exacerbates retinal detachment-induced photoreceptor cell death. Cell Death Dis 6: e1731, 2015.
147. Ito Y, Ofengeim D, Najafov A, Das S, Saberi S, Li Y, Hitomi J, Zhu H, Chen H, Mayo L, et al: RIPK1 mediates axonal degeneration by promoting inflammation and necroptosis in ALS. Science 353: 603-608, 2016.

148. Hébert MJ and Jevnikar AM: The impact of regulated cell death pathways on alloimmune responses and graft injury. Curr Transpl Rep 2: 242-258, 2015.

149. Lau A, Wang S, Jiang J, Haig A, Pavlosky A, Linkermann A, Zhang ZX and Jevnikar AM: RIPK3-mediated necroptosis promotes donor kidney inflammatory injury and reduces allograft survival. Am J Transplant 13: 2805-2818, 2013.

150. Becker DS: Toxic epidermal necrolysis. Lancet 351: 1417-1420, 1998.

151. Kim SK, Kim WJ, Yoon JH, Ji JH, Morgan MJ, Cho H, Kim YC and Kim YS: Upregulated RIP3 expression potentiates MLKL phosphorylation-mediated programmed necrosis in toxic epidermal necrolysis. J Investi Dermatol 135: 2021-2030, 2015.

This work is licensed under a Creative Commons Attribution-NonCommercial-NoDerivatives 4.0 International (CC BY-NC-ND 4.0) License. 